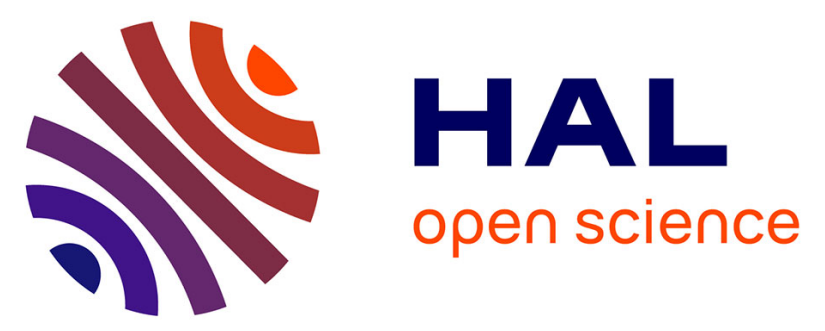

\title{
Conséquences endocriniennes, osseuses et métaboliques des greffes de cellules souches hématopoïétiques allogéniques chez l'adulte
}

Vianney Deméocq

\section{- To cite this version: \\ Vianney Deméocq. Conséquences endocriniennes, osseuses et métaboliques des greffes de cellules souches hématopoïétiques allogéniques chez l'adulte. Sciences du Vivant [q-bio]. 2017. dumas- 01662133}

\section{HAL Id: dumas-01662133 https://dumas.ccsd.cnrs.fr/dumas-01662133}

Submitted on 12 Dec 2017

HAL is a multi-disciplinary open access archive for the deposit and dissemination of scientific research documents, whether they are published or not. The documents may come from teaching and research institutions in France or abroad, or from public or private research centers.
L'archive ouverte pluridisciplinaire HAL, est destinée au dépôt et à la diffusion de documents scientifiques de niveau recherche, publiés ou non, émanant des établissements d'enseignement et de recherche français ou étrangers, des laboratoires publics ou privés.

\section{(이) $\$$}

Distributed under a Creative Commons Attribution - NonCommercial - NoDerivatives 44.0 
UNIVERSITE DE BREST - BRETAGNE OCCIDENTALE

Faculté de Médecine \& des Sciences de la Santé

Année 2017

$\mathbf{N}^{\circ}$

THESE DE

DOCTORAT EN MEDECINE

DIPLOME D'ETAT

Par

Mr DEMÉOCQ Vianney

Né le 29 juillet 1988 à BREST (29)

Présentée et soutenue publiquement le 4 octobre 2017

Conséquences endocriniennes, osseuses et métaboliques

des greffes de cellules souches hématopoïétiques

allogéniques chez l'adulte

Président : $\quad$ Mr le Professeur Christian BERTHOU

Membres du Jury : $\quad$ Mme le Professeur Véronique KERLAN

Mr le Professeur Jacques DELARUE

Mme le Docteur Marie-Anne COUTURIER

Mme le Docteur Sandra LESVEN 


\section{Doyens honoraires}

Professeur FLOCH Hervé

Professeur LE MENN Gabriel $(\dagger)$

Professeur SENECAIL Bernard

Professeur BOLES Jean-Michel

Professeur BIZAIS Yves $(\boldsymbol{t})$

Professeur DE BRAEKELEER Marc $(\dagger)$

Doyen

\section{Professeur BERTHOU Christian}

Professeurs émérites

$\begin{array}{ll}\text { CENAC Arnaud } & \text { Médecine interne } \\ \text { COLLET Michel } & \text { Gynécologie obstétrique } \\ \text { LEHN Pierre } & \text { Biologie cellulaire } \\ \text { YOUINOU Pierre } & \text { Immunologie }\end{array}$

Professeurs des Universités - Praticiens Hospitaliers en surnombre

$\begin{array}{ll}\text { LEFEVRE Christian } & \text { Anatomie } \\ \text { MOTTIER Dominique } & \text { Thérapeutique } \\ \text { RICHE Christian } & \text { Pharmacologie fondamentale }\end{array}$

Professeurs des Universités - Praticiens Hospitaliers de Classe Exceptionnelle

\begin{tabular}{ll} 
BOLES Jean-Michel & Réanimation \\
COCHENER-LAMARD Béatrice & Ophtalmologie \\
DEWITTE Jean-Dominique & Médecine et santé au travail \\
FEREC Claude & Génétique \\
GILARD Martine & Cardiologie \\
JOUQUAN Jean & Médecine interne \\
OZIER Yves & Anesthésiologie-réanimation \\
ROBASZKIEWICZ Michel & Gastroentérologie \\
& \\
Professeurs des Universités - Praticiens & Hospitaliers de ${ }^{\text {ère }}$ Classe \\
\hline & \\
BAIL Jean-Pierre & Chirurgie digestive \\
BERTHOU Christian & Hématologie \\
BLONDEL Marc & Biologie cellulaire \\
BOTBOL Michel & Pédopsychiatrie \\
BRESSOLLETTE Luc & Chirurgie vasculaire \\
CARRE Jean-Luc & Biochimie et biologie moléculaire \\
DE PARSCAU DU PLESSIX Loïc & Pédiatrie \\
DELARUE Jacques & Nutrition
\end{tabular}


DEVAUCHELLE-PENSEC Valérie

DUBRANA Frédéric

FENOLL Bertrand

FOURNIER Georges

GENTRIC Armelle

GOUNY Pierre

HU Weiguo

KERLAN Véronique

LACUT Karine

LE MEUR Yannick

LE NEN Dominique

LEROYER Christophe

LOZAC'H Patrick

MANSOURATI Jacques

MARIANOWSKI Rémi

MERVIEL Philippe

MISERY Laurent

NEVEZ Gilles

NONENT Michel

PAYAN Christopher

REMY-NERIS Olivier

SALAUN Pierre-Yves

SARAUX Alain

SIZUN Jacques

STINDEL Éric

TIMSIT Serge

VALERI Antoine

WALTER Michel
Rhumatologie

Chirurgie orthopédique et traumatologique

Chirurgie infantile

Urologie

Gériatrie et biologie du vieillissement

Chirurgie vasculaire

Chirurgie plastique, reconstructrice et esthétique

Endocrinologie, diabète et maladies métaboliques

Thérapeutique

Néphrologie

Chirurgie orthopédique et traumatologique

Pneumologie

Chirurgie digestive

Cardiologie

Oto-rhino-laryngologie

Gynécologie obstétrique

Dermato-vénérologie

Parasitologie et mycologie

Radiologie et imagerie médicale

Bactériologie-virologie

Médecine physique et réadaptation

Biophysique et médecine nucléaire

Rhumatologie

Pédiatrie

Biostatistiques, informatique médicale et technologies de communication

Neurologie

Urologie

Psychiatrie d'adultes

Professeurs des Universités - Praticiens Hospitaliers de $2{ }^{\text {ème }}$ Classe

\author{
ANSART Séverine \\ AUBRON Cécile \\ BEN SALEM Douraied \\ BERNARD-MARCORELLES Pascale \\ BEZON Eric \\ BROCHARD Sylvain \\ COUTURAUD Francis \\ DAM HIEU Phong \\ DELLUC Aurélien \\ GIROUX-METGES Marie-Agnès \\ HERY-ARNAUD Geneviève \\ HUET Olivier \\ LE MARECHAL Cédric \\ LE ROUX Pierre-Yves \\ L'HER Erwan \\ LIPPERT Éric \\ MONTIER Tristan \\ NOUSBAUM Jean-Baptiste \\ PRADIER Olivier
}

Maladies infectieuses

Réanimation

Radiologie et imagerie médicale

Anatomie et cytologie pathologiques

Chirurgie thoracique et cardiovasculaire

Médecine physique et réadaptation

Pneumologie

Neurochirurgie

Médecine interne

Physiologie

Bactériologie-virologie

Anesthésiologie-réanimation

Génétique

Biophysique et médecine nucléaire

Réanimation

Hématologie

Biologie cellulaire

Gastroentérologie

Cancérologie 
RENAUDINEAU Yves

SEIZEUR Romuald
Immunologie

Anatomie

Professeurs des Universités de Médecine Générale

\section{LE RESTE Jean-Yves \\ LE FLOC'H Bernard}

Professeur Associé des Universités de Médecine Générale (à mi-temps)

BARRAINE Pierre

Professeur des Universités contrat LRU

BORDRON Anne Biologie cellulaire

Maîtres de Conférences des Universités - Praticiens Hospitaliers Hors Classe

$\begin{array}{ll}\text { JAMIN Christophe } & \begin{array}{l}\text { Immunologie } \\ \text { MOREL Frédéric }\end{array} \\ \text { Biologie et médecine du développement et de la } \\ \text { reproduction } \\ \text { Anatomie }\end{array}$


Maîtres de Conférences de Médecine Générale

NABBE Patrice

Maîtres de Conférences Associés de Médecine Générale (à mi-temps)

BARAIS Marie

CHIRON Benoît

DERRIENNIC Jérémy

Maîtres de Conférences des Universités de Classe Normale

BERNARD Delphine

DERBEZ Benjamin

KARCHER Brigitte

LANCIEN Frédéric

LE CORRE Rozenn

MIGNEN Olivier

MORIN Vincent
Biochimie et biologie moléculaire

Sociologie démographie

Psychologie clinique

Physiologie

Biologie cellulaire

Physiologie

Electronique et informatique

Maître de Conférences Associé des Universités (à temps complet)

MERCADIE Lolita

Rhumatologie

Maître de Conférences des Universités contrat LRU

DANY Antoine

Epidémiologie et santé publique

GILLES Marlène

Génie informatique, automatique et traitement du signal

Professeurs certifiés / agrégés du second degré

MONOT Alain

RIOU Morgan
Français

Anglais 


\title{
UNIVERSITE DE BREST - BRETAGNE OCCIDENTALE \\ Faculté de Médecine \& des Sciences de la Santé
}

$* * * * *$

\section{AUTORISATION D'IMPRIMER}

\begin{abstract}
$* * * *$
Présentée par Monsieur le Professeur BERTHOU

Titre de la thèse (en MAJUSCULES) :

CONSÉQUENCES ENDOCRINIENNES, OSSEUSES ET METABOLIQUES DES GREFFES DE CELLULES SOUCHES HÉMATOIIÉTIQUES ALLOGÉNIQUES CHEZ L'ADULTE
\end{abstract}

ACCORD DU PRESIDENT DU JURY DE THESE SUR L'IMPRESSION DE LA THESE OUI :

NON : $\square$

En foi de quoi la présente autorisation d'imprimer sa thèse est délivrée à

Monsieur DEMÉOCQ Vianney

Interne en DES d'Endocrinologie, Diabète et Maladies Métaboliques

Fait à BREST, le $27 \log / 2017$

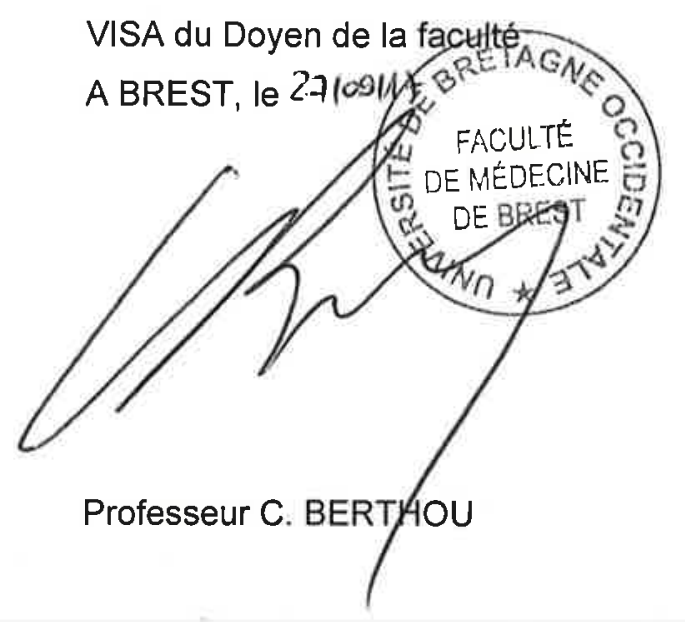

Le(a) Président(e) du Jury de Thèse,

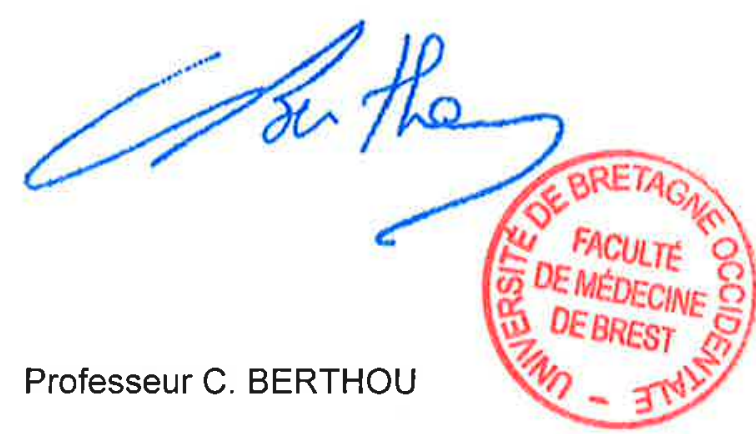




\section{Table des matières}

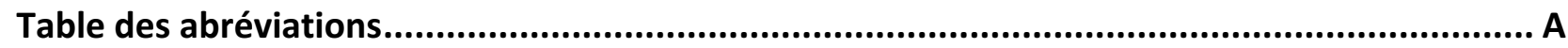

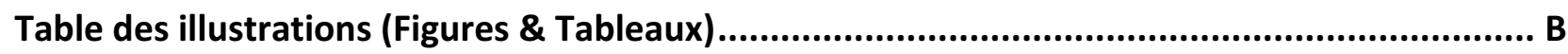

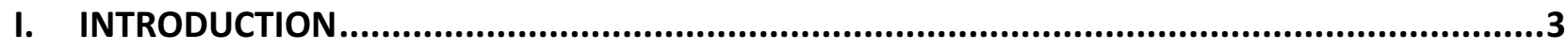

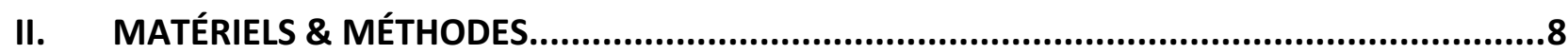

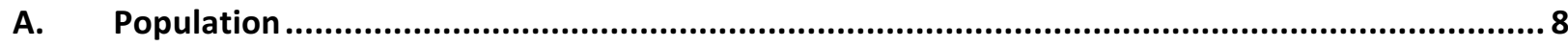

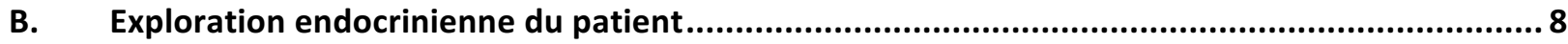

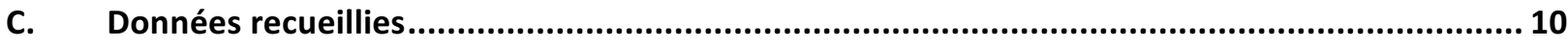

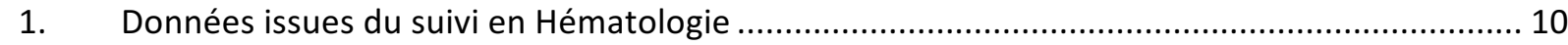

2. Données issues de l'exploration en Endocrinologie.............................................................. 10

D. Interprétation des données de l'évaluation endocrinienne .................................................. 11

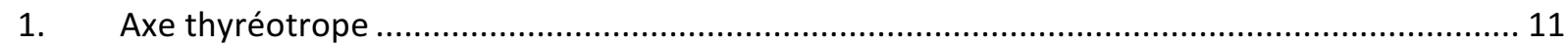

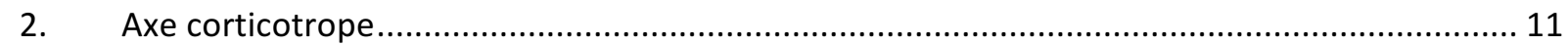

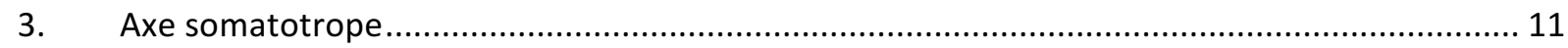

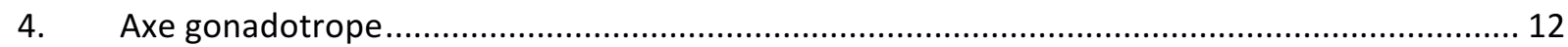

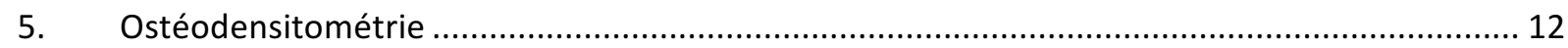

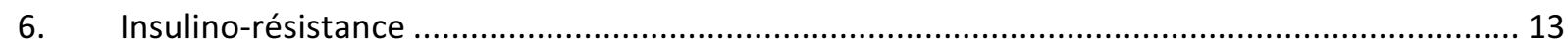

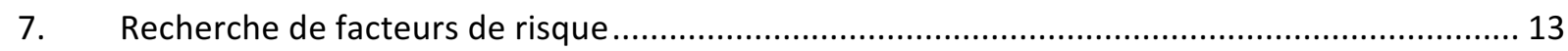

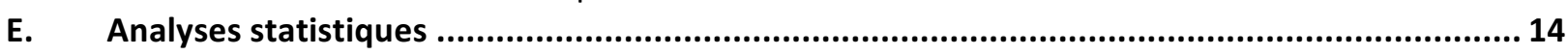

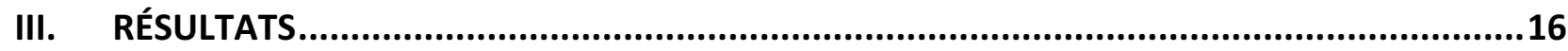

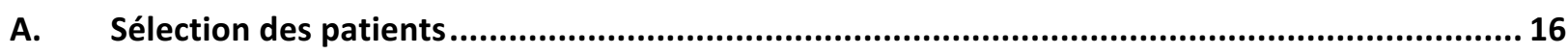

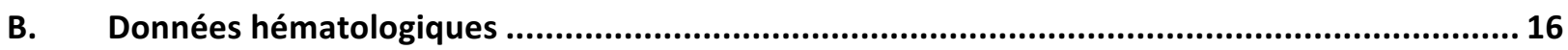

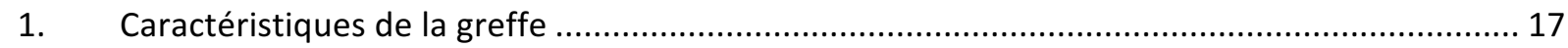

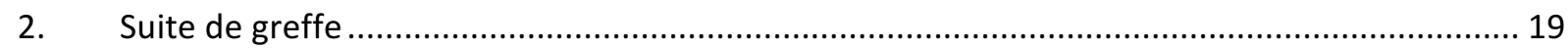

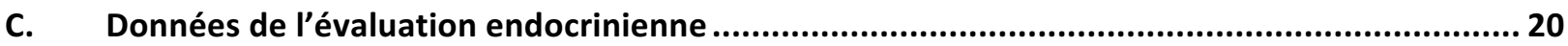

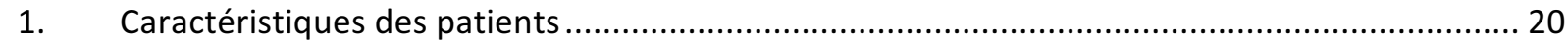

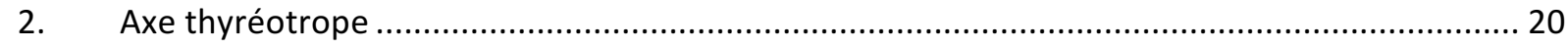

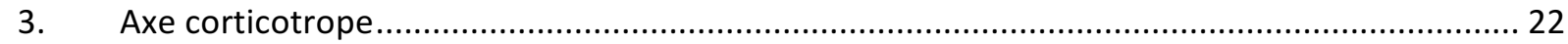

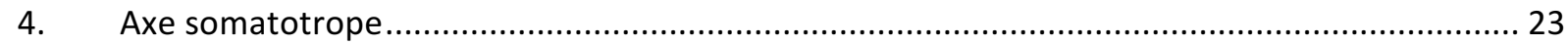

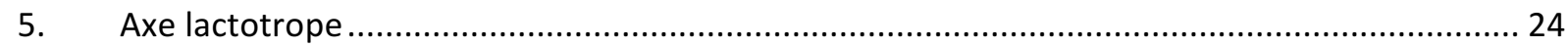

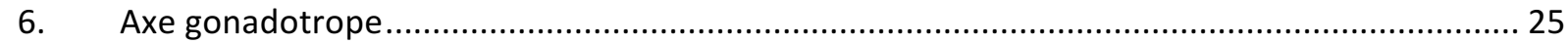

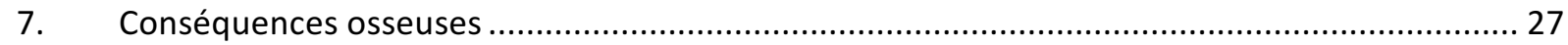

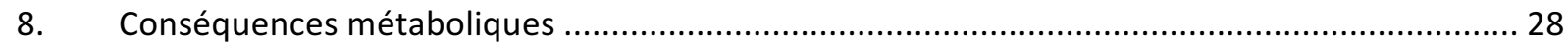

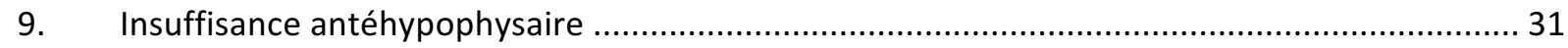

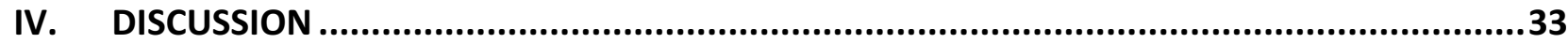

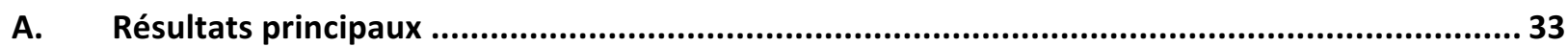

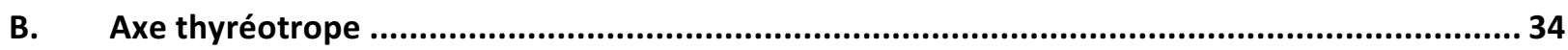

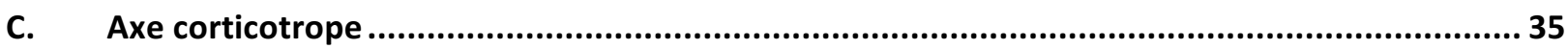

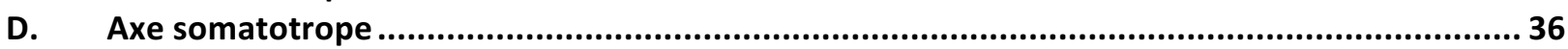

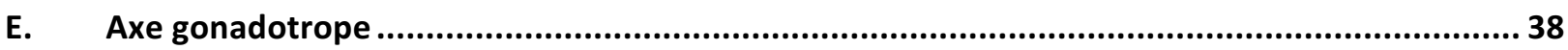

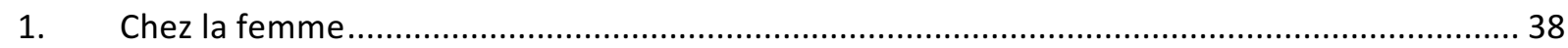

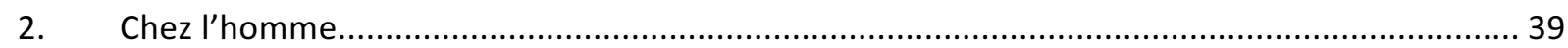

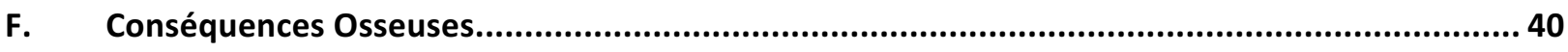

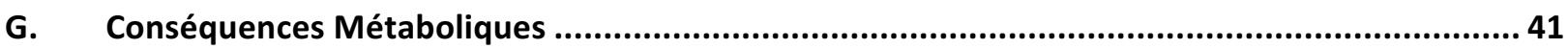

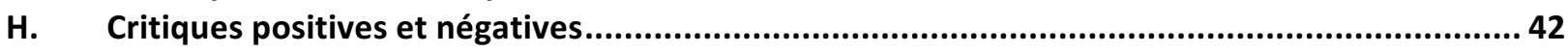

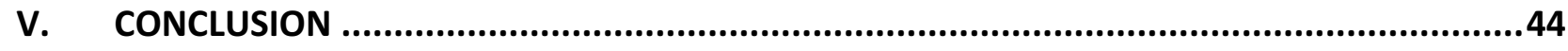

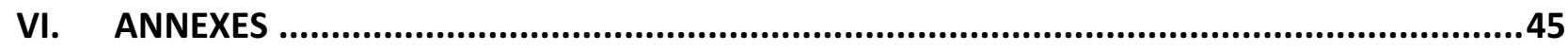

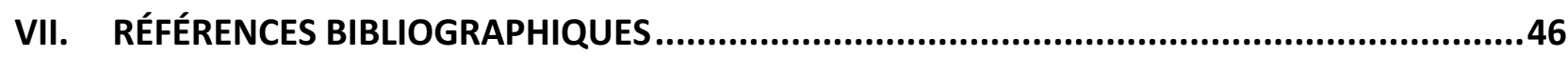




\section{Table des abréviations}

\begin{tabular}{|c|c|}
\hline ACTH & Adrenocorticotropic Hormone \\
\hline CSM & Cellules souches mésenchymateuses \\
\hline CSP & Cellules souches hématopoïétiques périphériques \\
\hline DMO & Densité minérale osseuse \\
\hline ECG & Électrocardiogramme \\
\hline FSH & Follicle Stimulating Hormone \\
\hline GVHD & Graft vs Host Disease \\
\hline $\mathrm{GH}$ & Growth Hormone \\
\hline GHRH & Growth Hormone-Releasing Hormone \\
\hline HDL & High-Density Lipoprotein \\
\hline HLA & Human Leukocyte Antigen \\
\hline HOMA-IR & Homeostasis Model Assessment-Insulino Resistance \\
\hline ICT & Irradiation Corporelle Totale \\
\hline IGF1 & Insulin-like Growth Factor 1 \\
\hline IMC & Indice de Masse Corporelle \\
\hline IOP & Insuffisance Ovarienne Primitive \\
\hline LDL & Low-Density Lipoprotein \\
\hline $\mathrm{LH}$ & Luteinizing Hormone \\
\hline TA & Tension Artérielle \\
\hline TSH & Thyroid-Stimulating Hormone \\
\hline USP & Unité de sang placentaire \\
\hline
\end{tabular}




\section{Table des illustrations (Figures \& Tableaux)}

Tableau 1 Études traitant de l'ensemble des conséquences hormonales suite à une allogreffe à l'âge post-pubère.

Tableau 2 Facteurs de risque de survenue de troubles endocriniens chez les patients allogreffés et/ou la population générale rapportés par la littérature.

Figure $1 \quad$ Flowchart de sélection des patients avant l'inclusion.

Tableau $3 \quad$ Caractéristiques hématologiques de la population incluse dans l'étude.

Figure 2 Répartition des âges au moment de la greffe.

Figure 3 Répartition des pathologies hématologiques des patients inclus.

Figure $4 \quad$ Répartition des types de donneurs.

Figure $5 \quad$ Répartition des types de greffon.

Figure $6 \quad$ Répartition des types de prophylaxie de la GVHD.

Tableau $4 \quad$ Caractéristiques lors de l'évaluation endocrinienne de la population incluse dans l'étude.

Tableau $5 \quad$ Critères prédictifs de survenue d'hypothyroïdie toute cause.

Tableau $6 \quad$ Critères prédictifs de survenue d'insuffisance corticotrope.

Tableau 7 Critères prédictifs de survenue d'insuffisance somatotrope (sévère et modérée).

Tableau $8 \quad$ Critères prédictifs d'élévation de la FSH chez l'homme.

Tableau 9 Critères prédictifs de diminution de la DMO et de l'ostéoporose.

Tableau 10 Comparaison de l'HOMA2-IR selon différents critères.

Annexe 1 Critères prédictifs de survenue d'hypothyroïdie périphérique (vraie et infraclinique).

Annexe 2 Critères prédictifs de survenue d'insuffisance somatotrope sévère. 


\section{INTRODUCTION}

La transplantation (ou greffe) de cellules souches hématopoïétiques est utilisée comme traitement d'hémopathies en Europe depuis 50 ans et sa fréquence dépasse aujourd'hui 30000 greffes par an. Les pathologies traitées sont principalement des leucémies aigues et des syndromes myélodysplasiques pour les transplantations allogéniques, dites allogreffes.

L'allogreffe consiste en l'injection de cellules souches hématopoïétiques d'un donneur différent du receveur porteur de l'hémopathie. Elle suppose un donneur compatible avec le receveur vis à vis de leur système majeur d'histocompatibilité (le système HLA [Human Leukocyte Antigen]). Le donneur peut être un donneur compatible issu de la fratrie, la greffe est dite géno-identique, ou un donneur compatible issu du fichier de donneurs volontaires de moelle osseuse, la greffe est dite phéno-identique. Enfin, dans certains cas, la source de cellules souches hématopoïétiques provient d'unités de sang placentaire le plus compatible possible ; la greffe est dite haplo-identique.

Un conditionnement est nécessaire avant l'allogreffe afin d'éviter le rejet de la greffe et afin, le cas échéant, d'éradiquer la maladie tumorale initiale. Elle comprend une chimiothérapie à forte dose, parfois associée à une irradiation corporelle totale (ICT). Dans certains cas, le conditionnement peut être d'intensité réduite, notamment pour les sujets les plus âgés.

Les principales particularités de l'allogreffe par rapport à l'autogreffe, où le donneur et le receveur sont la même personne, consistent en son effet curateur de l'hémopathie et en la nécessité de traitements immuno-modulateurs pour prévenir les conflits immunologiques entre donneur et receveur. La réaction du greffon contre l'hôte (graft versus host disease/GVHD) est une complication immunologique fréquente de l'allogreffe qui peut atteindre théoriquement $n^{\prime}$ importe quel organe du receveur. 50 à $70 \%$ des patients développent une GVHD dans les 10 ans après I'allogreffe. ${ }^{1}$

Les progrès en nombre et performance de la transplantation de ces dernières décennies sont accompagnés d'une augmentation significative de survivants à long terme. On estime aujourd'hui le nombre de survivants de transplantation de cellules hématopoïétiques à plus de 500000 personnes dans le monde. ${ }^{2}$ Les praticiens sont alors confrontés à une prévention et à un diagnostic précoce des complications immédiates ou tardives de la transplantation qui altèrent significativement la qualité de vie des patients. ${ }^{3}$

Une large étude rétrospective, portant sur 1087 patients survivants d'hémopathies, a montré que la fréquence à 5 ans des complications non-malignes après greffe est de $45 \%$ pour les greffes autologues et de $79 \%$ pour les greffes allogéniques. ${ }^{4}$

Le système endocrinien est très souvent atteint après greffe de moelle osseuse, avec près de deux tiers des complications possibles. ${ }^{5}$

Les complications endocriniennes touchent de nombreux organes, comme la thyroïde, les gonades, l'hypophyse et l'os. De plus, il existe une majoration du risque de syndrome métabolique secondaire aux greffes de moelle osseuse. Leur survenue dépend de la pathologie hématologique initiale, des traitements antérieurs à la greffe, et des modalités 
de conditionnement de la greffe dont l'irradiation corporelle totale (ICT) et chimiothérapie (nature et dose).

Néanmoins, la majorité des données disponibles sur la survenue des complications endocriniennes font référence à des populations pédiatriques.

\section{a) Conséquences endocriniennes de l'allogreffe pendant l'enfance}

L'hypothyroïdie est fréquente. Jusqu'à $20 \%$ des adultes allogreffés dans l'enfance développent une hypothyroïdie périphérique et 9,3\% une insuffisance thyréotrope sur un suivi de 28 ans. ${ }^{6}$ L'ICT est un facteur de risque majeur avec une incidence allant alors jusqu'à $50 \%$ d'hypothyroïdie périphérique. ${ }^{6}$ Certaines chimiothérapies ont également un effet thyrotoxique, notamment le busulfan en association au cyclophosphamide. ${ }^{7}$ Un jeune âge ${ }^{6,8,9}$ et le sexe féminin pourraient aussi augmenter le risque de survenue d'hypothyroïdie. $^{10}$

L'insuffisance corticotrope survient généralement après une corticothérapie au long cours, utilisée pour son effet immunosuppresseur comme traitement de la GVHD. Sa fréquence chez l'enfant allogreffé est comprise entre $7 \%$ et $24 \%$, avec comme facteur de risque I'ICT. $^{11,12}$

L'insuffisance somatotrope est une complication bien étudiée chez l'enfant puisqu'elle impacte leur croissance. La fréquence de l'insuffisance somatotrope chez les enfants allogreffés est comprise entre $17 \%$ et $50 \%{ }^{11,13-15}$ L'ICT, notamment $^{\prime}$ à un jeune âge, est prédictive d'une insuffisance somatotrope chez l'enfant. ${ }^{16}$ L'association $^{\prime}$ busulfan-cyclophosphamide pour le conditionnement de la greffe pourrait également être prédictive d'un déficit, mais les études sont contradictoires. ${ }^{17}$ La GVHD est également incriminée dans la survenue d'insuffisance somatotrope, par son effet dysimmunitaire $\mathrm{d}^{\prime}$ après certains auteurs, ${ }^{18}$ ou à cause de la corticothérapie associée pour d'autre. ${ }^{12}$

Chez l'enfant traité pour un cancer par chimiothérapie et radiothérapie, il existe de nombreux troubles pubertaires allant de la puberté précoce à l'absence de développement pubertaire.

Après allogreffe, l'insuffisance ovarienne primitive (IOP) atteint entre 65 et $84 \%$ des jeunes filles. ${ }^{19}$ La radiothérapie et la chimiothérapie, notamment par agents alkylants incluant le busulfan, ${ }^{20}$ sont cytotoxiques sur les follicules et leurs cellules de soutien avec un effet dose-dépendant. ${ }^{21}$ Un âge avancé lors de l'allogreffe est un facteur de risque d'IOP. ${ }^{19}$

Chez le jeune garçon, jusqu'à $100 \%$ ont une FSH (Follicle Stimulating Hormone) élevée après $I C T$, reflétant une atteinte de la spermatogenèse. En l'absence d'ICT, l'élévation de la FSH est estimée à $17 \%{ }^{15}$ et la GVHD est un facteur de risque. ${ }^{22}$ Les enfants traités par agents alkylants, dont le busulfan et le melphalan, peuvent avoir dans $90 \%$ des cas une azoospermie. ${ }^{20}$ Un jeune âge au moment du traitement est un facteur protecteur. ${ }^{20,23}$

Concernant l'atteinte osseuse, $50 \%$ des enfants allogreffés ont une déminéralisation osseuse lorsqu'ils atteignent l'âge adulte. ${ }^{24}$ Dans une large étude de suivi, cette déminéralisation est responsable de $5 \%$ de fractures sur 85 mois de suivi en moyenne. ${ }^{25}$ De nombreux facteurs sont impliqués dans la survenue de la déminéralisation 
osseuse des allogreffés comme la chimiothérapie, l'irradiation osseuse, la corticothérapie et donc la GVHD, les inhibiteurs de la calcineurine comme la ciclosporine, le méthotrexate, le déficit en vitamine $D$, l'hypogonadisme et un âge supérieur à 10 ans lors de l'allogreffe. ${ }^{24,26-}$ 28

Il est décrit un syndrome métabolique post-transplantation avec une insulinorésistance, un état pro-thrombotique et inflammatoire, une dyslipidémie, une HTA, et une répartition abdominale et viscérale des graisses. ${ }^{29}$ Après une allogreffe dans l'enfance, 40 à $50 \%$ des patients devenus adultes souffrent de dyslipidémies et jusqu'à $21 \%$ de diabète. ${ }^{1} \mathrm{~A}$ un an post-greffe, $12 \%$ des enfants ont un index de résistance augmenté sur l'HOMA-IR (Homeostasis Model Assessment-Insulino Resistance), pouvant aller jusqu'à $88 \%$ des cas à l'âge adulte en cas de conditionnement avec ICT. ${ }^{30}$ Les glucocorticoïdes et certains immunosuppresseurs majorent également l'insulino-résistance. ${ }^{31}$ D'autres facteurs se surajoutent comme l'hyperferritinémie secondaire aux transfusions itératives, ${ }^{32}$ l'hypogonadisme, l'hypothyroïdie et l'insuffisance somatotrope. Cette majoration du syndrome métabolique des survivants de cancer dans l'enfance majore, avec les effets des thérapeutiques anti-néoplasiques (comme l'anthracycline), le risque cardiovasculaire de sept fois par rapport à celui de la population générale. ${ }^{33}$

\section{b) Conséquences endocriniennes de l'allogreffe à l'âge l'adulte}

La littérature sur les conséquences endocriniennes de l'allogreffe réalisée à un âge adulte est plus pauvre et disparate. En effet, seulement 4 études se sont intéressées à l'ensemble des conséquences hormonales secondaires à une allogreffe réalisée à l'âge adulte ou après la puberté. ${ }^{34-37}$ Leurs caractéristiques et principaux résultats sont présentés dans le Tableau 1.

\begin{tabular}{|c|c|c|c|c|c|c|c|c|c|}
\hline Etude & $\begin{array}{l}\text { Nb de patients } \\
\quad(\mathrm{n}, \mathrm{H} / \mathrm{F})\end{array}$ & $\begin{array}{l}\text { Âge à } \\
\text { l'allogreffe } \\
\text { (ans) }\end{array}$ & Condit. & $\begin{array}{c}\text { ICT } \\
\% \text { (dose) }\end{array}$ & $\begin{array}{l}\text { Durée post-greffe } \\
\text { à l'exploration } \\
\text { hormonale } \\
\text { Moyenne (min- } \\
\text { max) }\end{array}$ & Axe thyréotrope & $\begin{array}{l}\text { Axe corticotrope } \\
\text { (type d'évaluation) }\end{array}$ & $\begin{array}{l}\text { Axe somatotrope } \\
\text { (type d'évaluation) }\end{array}$ & Axe gonadotrope \\
\hline $\begin{array}{l}\text { Benker et } a l^{34} \\
\text { (1989) }\end{array}$ & $23,10 / 13$ & $30(17-45)$ & $\begin{array}{l}\mathrm{CY}+\mathrm{ICT} \\
\text { ou CY }\end{array}$ & $\begin{array}{c}70 \% \\
(8,6 \mathrm{~Gy})\end{array}$ & 12-72 mois & $\begin{array}{l}\text { Hypothyroödie vraie : } 0 \\
\text { Hypothyroïdie infracl.: } 17,4 \%\end{array}$ & $0 \%(\mathrm{CRH})$ & $\begin{array}{l}\text { Moyenne du pic de GH } \\
\text { sous GHRH-Arginine : } \\
9,1 \mu \mathrm{g} / \mathrm{l}+/-1,35 \\
\text { vs } 23,3 \mu \mathrm{g} / \mathrm{l}+/-7,67 \\
\text { (groupe contrôle) } \\
\text { Pas d'incidence donnée }\end{array}$ & $\begin{array}{c}\text { Femme : } 61 \% \text { d'IOP/MNP des } \\
\text { femmes avec TBI } \\
\text { Homme : } 100 \% \text { de FSH élevée, } \\
\text { Hypogonadisme : } 0, \\
\text { FR: ICT }\end{array}$ \\
\hline $\begin{array}{l}\text { Littley et } a l^{35} \\
\quad \text { (1991) }\end{array}$ & $21,11 / 10$ & $26,2(16-49)$ & $\begin{array}{l}\text { CY ou Melph. } \\
+ \text { ICT }\end{array}$ & $\begin{array}{c}100 \% \\
(10-13 \mathrm{~Gy})\end{array}$ & 17-55 mois & $\begin{array}{c}\text { Hypothyroïdie vraie : } 0 \\
\text { Hypothyroïdie infracl.: } 28,6 \% \\
\text { FR : ICT }\end{array}$ & $\begin{array}{l}0 \% \text { (hypoglycémie } \\
\text { insulinique) }\end{array}$ & $\begin{array}{l}0 \% \text { (hypoglycémie } \\
\text { insulinique) }\end{array}$ & $\begin{array}{c}\text { Femme : } 100 \% \text { d'IOP/MNP } \\
\text { Homme : } 100 \% \text { de FSH élevée, } \\
60 \% \text { oligo-azoospermie, } \\
45 \% \text { hypogonadisme } \\
\text { compensée, } \\
0 \% \text { hypogonadisme, FR : ICT }\end{array}$ \\
\hline $\begin{array}{c}\text { Kauppila et } \text { al. }^{36} \\
\text { (1998) }\end{array}$ & $20,10 / 10$ & $39(16-50)$ & $\begin{array}{c}C Y+\mathrm{ICT} \\
\mathrm{ou} \mathrm{CY}+\mathrm{BU}\end{array}$ & $\begin{array}{c}75 \% \\
(8-10 G y)\end{array}$ & 38 mois $(12-120)$ & $\begin{array}{c}\text { Insuffisance thyréo. : } 5 \% \\
\text { Hypothyroïdie infracl. : } 5 \% \\
\text { Réponse exagérée } \\
\text { au test à la TRH : } 35 \% \\
\text { FR : ICT }\end{array}$ & $\begin{array}{c}5 \% \text { (synacthène } \\
250 \mu \mathrm{g} \text { ) }\end{array}$ & $\begin{array}{l}25 \% \text { (test GHRH- } \\
\text { Arginine) } \\
\text { Corrélation IMC }\end{array}$ & $\begin{array}{c}\text { Femme : } 90 \% \text { d'IOP/MNO } \\
\text { Homme : } 100 \% \text { de FSH élevée, } \\
40 \% \text { de LH élevée, } \\
0 \% \text { hypogonadisme }\end{array}$ \\
\hline $\begin{array}{c}\text { Tauchmanovà et } a l^{37} \\
\text { (2002) }\end{array}$ & $40,21 / 19$ & $29(13-45)$ & $\mathrm{CY}+\mathrm{BU}$ & Aucune & 36 mois (12-62) & $\begin{array}{l}\text { Hypothyroïdie vraie : } 0 \\
\text { Hypothyroïdie infracl. : 7,7\% } \\
\text { Syndrome de basse T3 : } 10 \%\end{array}$ & $\begin{array}{l}10 \% \text { (cortisol à 8h) } \\
\text { FR: corticothérapie }\end{array}$ & $\begin{array}{c}27 \% \text { (IGF1 de base) } \\
\text { FR : GVHD }\end{array}$ & $\begin{array}{c}\text { Femme : } 95 \% \text { d'IOP/MNP } \\
\text { Homme : } 47 \% \text { de FSH élevée, } \\
0 \% \text { hypogonadisme }\end{array}$ \\
\hline
\end{tabular}

Abréviations : Nb, Nombre; H, Homme; F, Femme; Condit., Conditionnement; ICT, Irradiation Corporelle Totale; CY; Cyclophosphamide; BU, Busulfan; Melph., Melphalan; FR, facteur de risque; infracl., infraclinique; IOP; insuffisance ovarienne primitive; MNP, ménopause

Tableau 1. Études traitant de l'ensemble des conséquences hormonales suite à une allogreffe à l'âge post-pubère. 
Trois autres études se sont consacrées à un ou deux troubles hormonaux :

- L'étude de Al-Hazzouri et al., prospective sur 181 patients adultes (18-68 ans), montre une fréquence à 3 ans post-greffe d'hypothyroïdie vraie de $8 \%$ lors d'un conditionnement myélo-ablatif avec ICT, et de $5 \%$ lors d'un conditionnement d'intensité réduite, sans différence significative. ${ }^{38}$

- L'étude de Thomas et al., rétrospective sur 186 adultes français de 36,5 ans en moyenne (15-60 ans), retrouvait une fréquence de 6,5 \% d'hypothyroïdie vraie à 4 ans post-ICT réalisée dans le cadre du conditionnement d'une greffe de moelle osseuse (68\% auto et $42 \%$ allogreffe). ${ }^{39}$

- L'étude de Garg et al., sur une population de patients greffés (22\% auto et $78 \%$ allogreffés), a évalué ses patients dans $43 \%$ des cas à moins d'un an de la greffe. L'analyse du groupe des adultes $(n=28)$, traités par busulfan et cyclophosphamide sans ICT retrouvait $100 \%$ d'IOP ou de ménopause chez les femmes. Chez les hommes, $100 \%$ étaient azoospermes, $79 \%$ avaient un hypogonadisme hypogonadotrope compensé ( $\mathrm{LH}$ [Luteinizing Hormone] augmentée et testostérone normale) et $10 \%$ un hypogonadisme hypergonadotrophique. Après test d'hypoglycémie insulinique, $36 \%$ des patients avaient une insuffisance somatotrope. $^{40}$

Concernant les atteintes osseuses, plusieurs études ont été réalisées chez l'adulte. L'étude prospective de Yao et al., portant sur 102 patients, montre une déminéralisation osseuse chez $50 \%$ des sujets dans les 6 mois post-greffe sans lien avec un traitement par corticothérapie. ${ }^{24}$ Schulte et al., dans une étude prospective de 280 patients, a montré, sur un suivi de 4 ans, une perte osseuse par an de 0,6\% au niveau vertébral, et de 2,3\% au niveau fémoral avec un pic à 6 mois post-greffe. Les facteurs de risque associés étaient la dose et la durée d'une corticothérapie, la durée de traitement par cyclosporine A et la perte de masse musculaire. ${ }^{41}$ Des études plus anciennes montraient une fréquence d'ostéoporose à 1 an post-greffe entre 7 et $20 \%$, et une baisse de la DMO (densité minérale osseuse) dans 39 à $53 \%$ des cas. $^{26,42,43}$

A notre connaissance, aucune étude ne s'est intéressée à l'impact métabolique des patients allogreffés à l'âge adulte.

\section{c) Objectifs de notre étude}

Les conséquences endocriniennes secondaires à une transplantation allogénique de cellules souches hématopoḯtiques restent peu évaluées dans leur ensemble chez les patients allogreffés à l'âge adulte. Pourtant, le dépistage et le traitement de ces complications sont susceptibles d'améliorer la qualité de vie de ces patients.

Ainsi, l'objectif principal de cette étude observationnelle et rétrospective était d'évaluer les conséquences endocriniennes de l'allogreffe sur une population greffée après la puberté et évaluée à l'âge adulte au CHRU de Brest.

Nous avons étudié les retentissements éventuels sur la fonction thyroïdienne, les différents axes hypophysaires (corticotrope, somatotrope, gonadotrope, thyréotrope et lactotrope), la fonction gonadique, la minéralisation osseuse et plusieurs paramètres 
métaboliques (Indice de Masse Corporelle [IMC], bilan lipidique et index d'insulinorésistance).

L'objectif secondaire de notre travail était de rechercher des critères prédictifs de survenue de ces conséquences endocriniennes, en étudiant notamment les facteurs de risque connus ou suspectés par la littérature. 


\section{MATÉRIELS \& MÉTHODES}

Il s'agit d'une étude rétrospective, observationnelle et monocentrique menée sur une cohorte de patients ayant subi une transplantation de cellules souches hématopoïétiques allogéniques dans le cadre d'une hémopathie maligne. Tous les patients étaient suivis dans le service d'hématologie du CHRU de Brest (Pr Christian BERTHOU).

\section{A. Population}

Les patients recrutés ont été greffés sur la période du $1^{\mathrm{er}}$ janvier 2006 au $1^{\mathrm{er}}$ juin 2016 dans le secteur protégé du CHRU de Brest (Dr Gaëlle GUILLERM).

Les critères d'inclusion étaient les suivants :

- Transplantation de cellules souches hématopoïétiques allogéniques,

- Dans le cadre d'une hémopathie maligne,

- Sujet majeur âgé de 18 à 75 ans lors de l'évaluation endocrinienne,

- Sujet en rémission complète lors de l'évaluation endocrinienne,

- Ayant donné leur consentement oral.

Les critères d'exclusion étaient les suivants :

- Les patients n'ayant pas été explorés dans le service d'endocrinologie,

- Les patients ayant déjà subi une autre transplantation de cellules souches hématopoïétiques allogéniques et/ou autogéniques,

- Radiothérapie encéphalique,

- Grossesse en cours ou allaitement.

\section{B. Exploration endocrinienne du patient}

Chaque patient allogreffé, en rémission complète à environ un an de la greffe, avait la possibilité de réaliser un dépistage des complications endocriniennes dans le service d’Endocrinologie du CHRU de Brest (Pr Véronique KERLAN).

Il était reçu en hôpital de jour pour un recueil de données cliniques et pour la réalisation d'explorations endocriniennes comprenant des dosages hormonaux de base, un ou plusieurs tests dynamiques pour explorer la fonction corticotrope et somatotrope, et une ostéodensitométrie osseuse sur deux sites (fémoral et vertébral). Tous les patients explorés ont donné leur consentement oral à la réalisation d'étude de recherche clinique.

Sauf contre-indication (antécédents d'épilepsie, AVC ou insuffisance coronarienne) ou corticothérapie en cours, chaque patient a bénéficié d'un test d'hypoglycémie insulinique sur la GH (Growth Hormone ou hormone de croissance) et le cortisol plasmatique à $8 \mathrm{~h}$.

- Patient à jeun depuis $12 \mathrm{~h}$, allongé pendant l'examen,

- Si traitement par Hydrocortisone : arrêt du traitement depuis la veille à $16 \mathrm{~h}$,

- Pose d'un cathéter court dans chaque veine brachiale,

- A TO : dosage de la glycémie, de la GH, de I'ACTH (Adrenocorticotropic Hormone) et du cortisol plasmatique, puis injection en IVD de $0,1 \mathrm{U} / \mathrm{kg}$ d'analogue de l'insuline rapide, 
- A T+15, T+30, T+45, T+60, T+90 min : dosage de la glycémie, de la GH, de l'ACTH et du cortisol plasmatique,

- Surveillance de la TA (Tension Artérielle) et de la glycémie capillaire tous les quarts d'heure. Réalisation d'un ECG (Électrocardiogramme) en cas de douleur thoracique. Injection de sérum glucosé si glycémie $<0,3 \mathrm{~g} / \mathrm{l}$ et/ou signes cliniques d'hypoglycémie, convulsions ou perte de connaissance.

En cas de contre-indication au test d'hypoglycémie insulinique, le patient bénéficiait de deux tests dynamiques :

- Pour l'exploration somatotrope:

- un test au glucagon-propranolol

- Patient à jeun depuis $12 \mathrm{~h}$, allongé pendant l'examen,

- Pose d'un cathéter court dans une veine brachiale,

- A T-30 min: dosage de la glycémie et de la $\mathrm{GH}$, puis ingestion de $0,75 \mathrm{mg} / \mathrm{kg}$ de propranolol sans dépasser la dose maximale de $40 \mathrm{mg}$,

- A T0 : dosage de la glycémie et de la GH, puis injection intramusculaire de $1 \mathrm{mg}$ de glucagon,

- A $T+30, T+60, T+90, T+120, T+150$ et $T+190$ min : dosage de la glycémie et de la $\mathrm{GH}$,

- Surveillance de la TA et de la fréquence cardiaque toutes les 15 min, ECG si bradycardie (pouls $<50 \mathrm{bpm}$ ).

ou un test à la GHRH-arginine (GHRH : Growth Hormone-Releasing Hormone)

- Patient à jeun depuis $12 \mathrm{~h}$, allongé pendant l'examen,

- Pose d'un cathéter court dans chaque veine brachiale,

- A T-15 min : dosage de la GH,

- A T0: dosage de la $\mathrm{GH}$ puis injection de $1 \mu \mathrm{g} / \mathrm{kg}$ de $\mathrm{GHRH}$ en intraveineux direct et perfusion sur $30 \mathrm{~min}$ de $0,5 \mathrm{~g} / \mathrm{kg}$ d'arginine, sans dépasser la dose maximale de $30 \mathrm{~g}$, diluée dans $500 \mathrm{ml}$ de $\mathrm{NaCl}$,

- $A T+15, T+30, T+45, T+60, T+90, T+120$ min : dosage de la $G H$,

- Surveillance de la TA et de la fréquence cardiaque toutes les $15 \mathrm{~min}$, ECG si tachycardie (pouls $>100 \mathrm{bpm}$ ).

- Pour l'exploration corticotrope : un test au Synacthène ${ }^{\circledR} 1 \mu \mathrm{g}$ [Tetracosactin ou corticotropin-(1-24)] :

- Patient à jeun ou non, allongé pendant l'examen,

- Si traitement par Hydrocortisone : arrêt du traitement depuis la veille à $16 \mathrm{~h}$,

- Pose d'un cathéter court dans une veine brachiale,

- A TO: dosage du cortisol plasmatique puis injection intraveineux direct de $1 \mu \mathrm{g}$ de Synacthène ${ }^{\circledR}$,

- A T+30, T+60 et T+90 min : dosage du cortisol plasmatique. 


\section{Données recueillies}

\section{Données issues du suivi en Hématologie}

Pour chaque patient étaient recueillis :

- Données démographiques

○ Nom, Prénom, date de naissance,

O Sexe,

- Type de pathologie hématologique,

- Date du diagnostic,

- Date de l'allogreffe et âge à la greffe.

- Caractéristiques de la greffe

- Statut de l'hémopathie lors de l'allogreffe,

- Type de conditionnement de l'allogreffe (myélo-ablatif ou d'intensité réduite) et ses modalités: irradiation corporelle totale et dose de rayonnement (en Gy), type de chimiothérapie,

- Sources des cellules souches hématopoïétiques (cellules souches périphériques, cellules souches mésenchymateuses, unités de sang placentaire),

- Type de donneurs (géno-identique, phéno-identique ou haplo-identique) et la compatibilité HLA/Groupe sanguin ABO/Sexe,

- Type de prophylaxie de la GVHD.

- Complications de la greffe jusqu'à l'exploration en Endocrinologie

- GVHD aigüe, sa localisation, sa sévérité et son traitement,

- GVHD chronique, sa localisation, sa sévérité et son traitement,

- Utilisation de corticothérapie comme traitement de la GVHD, sa dose, sa durée et la réponse de la GVHD à la corticothérapie.

Le diagnostic et la sévérité des GVHD est classifiée selon le consensus du NIH Consensus Development Project. ${ }^{44}$

\section{Données issues de l'exploration en Endocrinologie}

- Données démographiques

- Âge à l'exploration,

- Durée écoulée depuis l'allogreffe.

- Données cliniques

- Poids, taille, IMC,

- Signes cliniques d'un déficit endocrinien,

- Traitements en cours incluant notamment un traitement substitutif d'hormones sexuelles, une corticothérapie ou un traitement immunosuppresseur.

- Dosages hormonaux de base :

- TSH (Thyroid-stimulating Hormone) et thyroxine (T4) libre,

- IGF1 (Insulin-like Growth Factor 1),

- FSH, LH, estradiol chez la femme et testostérone totale chez l'homme,

- Prolactine. 
- Les résultats des tests dynamiques explorant les fonctions corticotrope et somatotrope

- Autres données biologiques: examen des anomalies lipidiques (Triglycérides, HDL[High-Density Lipoprotein], et LDL [Low-Density Lipoprotein] calculé), insulinémie, glycémie à jeun et vitamine D (25-OH D2-D3).

- Les résultats de l'ostéodensitométrie fémorale et vertébrale par l'absorptiométrie biphotonique aux rayons $X$.

\section{Interprétation des données de l'évaluation endocrinienne}

\section{Axe thyréotrope}

L'évaluation de l'axe thyréotrope a été réalisée selon les dosages de base de la TSH et de la T4 libre.

Définition :

- Hypothyroïdie périphérique vraie: TSH élevée et T4 libre abaissée, ${ }^{45}$

- Hypothyroïdie périphérique infraclinique : TSH élevée et T4 libre normale, ${ }^{46}$

- Hypothyroïdie centrale ou insuffisance thyréotrope: TSH basse ou normale et T4 libre abaissée. ${ }^{47}$

\section{Axe corticotrope}

L'évaluation de l'axe corticotrope a été réalisée selon les résultats des tests dynamiques. Les critères retenus sont ceux de l'Endocrine Society $:^{48}$

- Sur le test d'hypoglycémie insulinique: l'insuffisance en glucocorticoïdes est confirmée si la glycémie s'abaisse en dessous de $2,2 \mathrm{mmol} / \mathrm{l}(0,4 \mathrm{~g} / \mathrm{l})$ et si le cortisol plasmatique ne dépasse pas $20 \mu \mathrm{g} / \mathrm{dl}$.

- Sur le test au Synacthène ${ }^{\circledR} 1 \mu \mathrm{g}$ : I'insuffisance en glucocorticoïdes est confirmée si le cortisol plasmatique ne dépasse pas $18,1 \mu \mathrm{g} / \mathrm{dl}$.

L'insuffisance corticotrope (ou insuffisance surrénalienne centrale) est diagnostiquée en cas d'insuffisance en glucocorticoïdes sur un des tests dynamiques et si l'ACTH de base à $8 \mathrm{~h}$ est non-élevée, d'autant plus si elle est inférieure à $10 \mathrm{pmol} / \mathrm{l}$.

\section{Axe somatotrope}

L'évaluation de l'axe somatotrope a été réalisée selon les résultats des tests dynamiques. Les critères retenus sont :

- Sur le test d'hypoglycémie insulinique : l'insuffisance somatotrope est confirmée si la glycémie s'abaisse en dessous de $2,2 \mathrm{mmol} / \mathrm{l}(0,4 \mathrm{~g} / \mathrm{l})$ et si la $\mathrm{GH}$ ne dépasse pas $9 \mathrm{mUI} / \mathrm{l}$ pour une insuffisance sévère, ou entre 9 et $15 \mathrm{mUI} / \mathrm{l}$ pour une insuffisance partielle (Endocrine Society). ${ }^{48}$

- Sur le test au glucagon-propranolol : I'insuffisance somatotrope est confirmée si la GH ne dépasse pas $9 \mathrm{mUI} / \mathrm{l}$ pour une insuffisance sévère, ou entre 9 et $15 \mathrm{mUI} / \mathrm{I}$ pour une insuffisance partielle (Endocrine Society). ${ }^{48}$ 
- Sur le test à la GHRH-arginine : I'insuffisance somatotrope est confirmée si la GH ne dépasse pas $33 \mathrm{mUI} / \mathrm{I}$ pour un IMC $<25 \mathrm{~kg} / \mathrm{m}^{2}, 24 \mathrm{mUI} / \mathrm{I}$ pour un IMC entre 25$30 \mathrm{~kg} / \mathrm{m} 2$ ou $12 \mathrm{mUI} / \mathrm{I}$ pour un IMC $>30 \mathrm{~kg} / \mathrm{m}^{2}$ (GH Research Society). ${ }^{49}$

\section{Axe gonadotrope}

\section{a) Axe gonadotrope féminin}

Le diagnostic de ménopause était porté pour les patientes dont l'aménorrhée était antérieure à la prise en charge de l'hémopathie maligne et qui avaient, lors de l'évaluation dans le service d'endocrinologie, une FSH élevée et un estradiol plasmatique bas.

Le diagnostic d'insuffisance ovarienne primitive était porté pour les patientes dontl'aménorrhée était postérieure à la prise en charge de l'hémopathie maligne et qui avaient, lors de l'évaluation dans le service d'endocrinologie, une FSH élevée et estradiol bas.

Le diagnostic d'insuffisance gonadotrope était porté pour les patientes qui avaient une FSH normale ou basse et un estradiol bas, en l'absence de traitement substitutif.

\section{b) Axe gonadotrope masculin}

L'atteinte de la spermatogenèse, par une insuffisance sertolienne, était suspectée devant une élévation de la FSH.

Le diagnostic d'hypogonadisme hypogonadotrophique était porté pour les patients qui avaient un taux de testostérone total bas associé à un taux de LH normal ou bas.

Le diagnostic d'hypogonadisme hypergonadotrophique, ou insuffisance leydigienne/testiculaire, était porté pour les patients ayant une LH élevée et une testostérone basse.

\section{Ostéodensitométrie}

Les critères diagnostiques de l'ostéoporose non-fracturaire ont été définis par l'OMS en 1994 selon la densité minérale osseuse estimée par l'absorptiométrie biphotonique aux rayons $X{ }^{50}$ La valeur de la DMO est estimée par le T-score :

o T-score $\geq-1$ DS : normale,

- T-score entre -1 DS et $-2,5$ DS : ostéopénie,

○ T-score $\leq-2,5$ DS : ostéoporose.

Un déficit profond en vitamine $D$ était défini si sa concentration plasmatique était inférieure à $30 \mathrm{nmol} / \mathrm{l}$. 


\section{Insulino-résistance}

L'insulino-résistance a été estimée par la formule informatique de l'Homeostasis Model Assessment (HOMA2-IR) ${ }^{51}$ avec le HOMA Calculator en libre accès (https://www.dtu.ox.ac.uk/homacalculator/). La formule utilise la glycémie à jeun et l'insulinémie à jeun concomitante. La valeur seuil utilisée dans notre étude pour l'insulinorésistance était un $\mathrm{HOMA2-IR} \geq 1,21 .{ }^{52}$

\section{Recherche de facteurs de risque}

Nous avons recherché des critères prédictifs de survenue de troubles endocriniens en étudiant la corrélation entre la survenue de troubles endocriniens et les facteurs de risque rapportés par la littérature (Tableau 2). Nous n'avons pas réalisé d'étude de corrélation lorsque les effectifs des patients atteints étaient trop faibles pour réaliser une analyse statistique, ou lorsque l'ensemble des effectifs était atteint.

\begin{tabular}{|c|c|}
\hline $\begin{array}{c}\begin{array}{c}\text { Trouble } \\
\text { endocrinien }\end{array} \\
\end{array}$ & Facteurs risque suspectés ou décrits dans la littérature \\
\hline $\begin{array}{l}\text { Hypothyroïdie } \\
\text { périphérique }\end{array}$ & $\begin{array}{l}\text { Toxicité directe du conditionnement de l'allogreffe }{ }^{53} \text { irradiation, }^{54} \\
\text { âge jeune à l'irradiation, }{ }^{6} \text { GVHD chronique }{ }^{17} \text { sexe féminin. }{ }^{45}\end{array}$ \\
\hline $\begin{array}{l}\text { Insuffisance } \\
\text { corticotrope }\end{array}$ & $\begin{array}{l}\text { Corticothérapie à forte dose prolongée pour GVHD, } \\
\text { irradiation hypophysaire. }{ }^{55}\end{array}$ \\
\hline $\begin{array}{l}\text { Insuffisance } \\
\text { somatotrope }\end{array}$ & $\begin{array}{l}\text { Âge jeune à l'allogreffe, }{ }^{17} \text { irradiation hypophysaire, }{ }^{17} \text { association } \\
\text { busulfan/cyclophosphamide, }{ }^{17} \text { GVHD chronique et IMC bas. }{ }^{12}\end{array}$ \\
\hline $\begin{array}{l}\text { Troubles de la } \\
\text { spermatogenèse }\end{array}$ & $\begin{array}{l}\text { Âge } \geq 25 \text { ans à la greffe, ICT, GVHD si absence d'ICT, }{ }^{22} \text { agents alkylants } \\
\text { dont le busulfan (dose-dépendant). }{ }^{56}\end{array}$ \\
\hline Ostéoporose & $\begin{array}{l}\text { Âge }>50 \text { ans }{ }^{50} \text { insuffisance somatotrope, hypothyroïdie, insuffisance } \\
\text { gonadique, corticothérapie prolongée, immunosuppression prolongée, } \\
\text { LAL, administration de méthotrexate, GVHD chronique, carences } \\
\text { nutritionnelles et lésions osseuses post-radiques, }{ }^{57,58} \text { certaines } \\
\text { chimiothérapies, }{ }^{59} \text { carence en vitamine } D^{60}\end{array}$ \\
\hline Insulino-résistance & $\begin{array}{l}\text { Corticothérapie à forte dose prolongée, }{ }^{31} \text { traitement par } \\
\text { immunosuppresseurs, }{ }^{31} \text { lipodystrophie secondaire à la GVHD, }{ }^{61} \text { IMC } \\
\text { élevé, }{ }^{62} \text { insuffisance somatotrope, }{ }^{63} \text { âge et sexe, }{ }^{64} \text { hypothyroïdie, }{ }^{65} \\
\text { chimiothérapie. }\end{array}$ \\
\hline
\end{tabular}

Tableau 2. Facteurs de risque de survenue de troubles endocriniens chez les patients allogreffés et/ou la population générale rapportés par la littérature.

La GVHD étant possiblement impliquée dans la survenue de tous les troubles endocriniens, nous avons étudié la corrélation entre la survenue de ces troubles avec chaque paramètre impliqué dans la survenue ou la sévérité de la GVHD (type de prophylaxie, traitement par immunosuppresseurs à l'exploration endocrinienne, GVHD aigüe et/ou chronique, GVHD dépendante à la corticothérapie, GVHD chronique modérée ou sévère).

Le busulfan étant un possible facteur de risque d'atteinte somatotrope et donc antéhypophysaire, nous avons également étudié la corrélation entre le conditionnement par busulfan et l'axe corticotrope et thyréotrope. 
Nous insistons sur le fait que les facteurs de risque de la littérature sont, dans la très grande majorité des cas, retrouvés pour une population greffée dans l'enfance. Nos analyses statistiques sont nombreuses dans un but exploratoire chez l'adulte.

\section{E. Analyses statistiques}

La base de données a été constituée par l'investigateur. Les analyses statistiques ont été réalisées à l'aide du logiciel IBM ${ }^{\circledR}$ SPSS $^{\circledR}$ Statistics 20 après exclusion des données manquantes.

Les données des variables quantitatives sont exprimées en moyenne \pm écart-type, sauf mention contraire. Les moyennes sont comparées par un test de Student en cas de distribution normale ou par un test non-paramétrique de Mann-Whitney en l'absence de distribution normale.

Les données des variables qualitatives sont exprimées en termes d'effectifs et de fréquence, sauf mention contraire. Les distributions des variables qualitatives sont comparées à l'aide du test de $\mathrm{Chi}^{2}$ ou le test exact de Fisher selon les effectifs disponibles.

La différence est considérée comme significative pour une valeur de $\mathrm{P} \leq 0,05$.

${ }^{*}: P \leq 0,05, * *: P \leq 0,01, * * *: P \leq 0,001, * * * *: P \leq 0,0001$. 


\section{0 allogreffes pour 249 patients entre le 1er janvier 2006 et le 1er juin 2016}

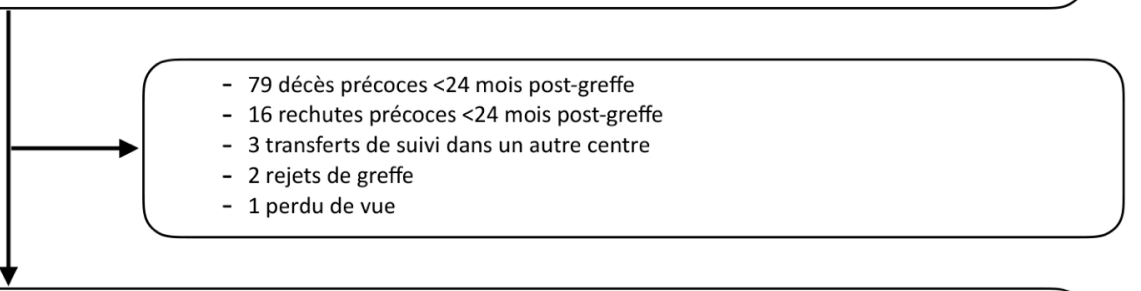

148 patients explorables en Endocrinologie

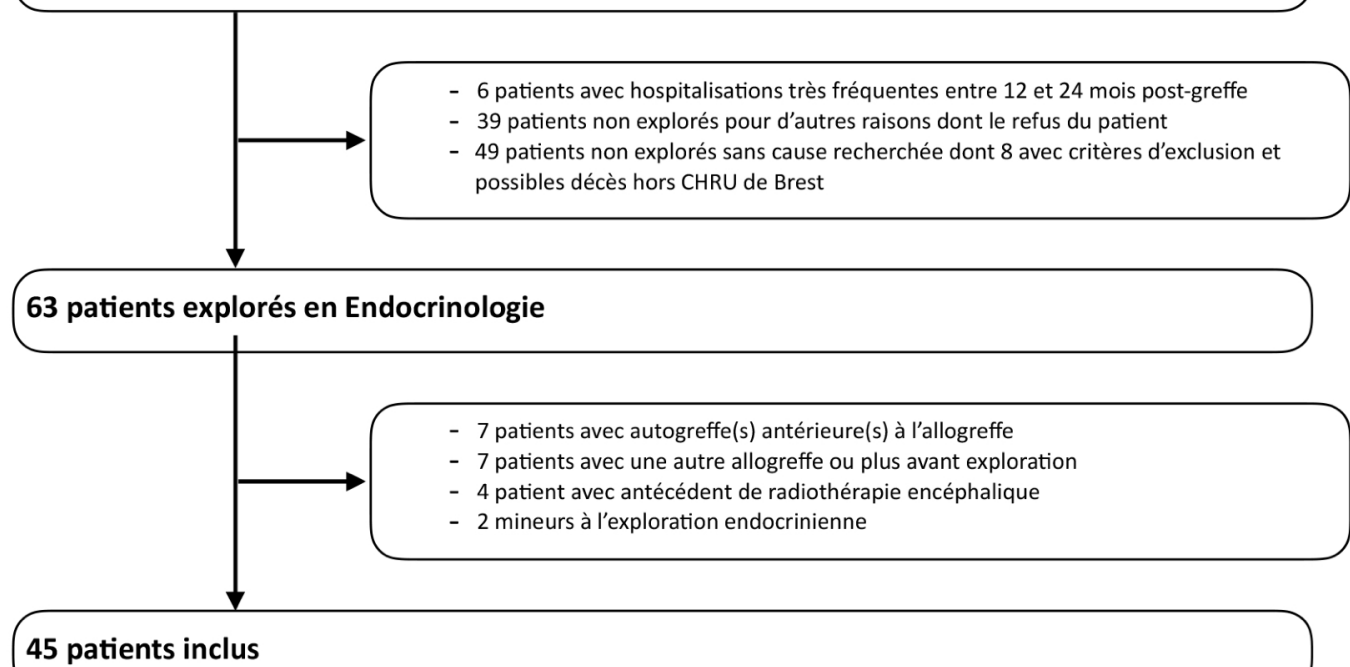

Figure 1. Flowchart de sélection des patients avant l'inclusion.

\section{Caractéristique}

Age à la greffe - année

$45,0 \pm 12,77$

Sexe - no. $(\%)$

$1,78 \pm 14,75$

Homme

$18(40)$

Femme
Type d'hémopathie - no. (\%)

LAM $27(60)$

$26(57,8)$

LAL $6(13,3)$

AREB $\quad 5(11,1)$

Autres $8(17,8)$

Statut de l'hémopathie à la greffe - no. (\%) $32(71,1)$
Rémission Complète

$\begin{array}{lr}\text { Rémission Complète } & 32(71,1) \\ \text { Rémission Partielle } & 6(13,3)\end{array}$

Réfractaire $\quad 7(15,6)$

Type de Conditionnement - no. (\%) $20(44,4)$

$20(44,4)$

$\begin{array}{lr}\text { Intensite Reduite } & 25(55,6) \\ \text { Irradiation Corporelle Totale - no. (\%) } & 8(17,8)\end{array}$

$\begin{array}{ll}\text { Irradiation Corporelle Totale - } & 8(17,8) \\ \text { Conditionnement par Busulfan/Fludarabine seul - no. (\%) } & 28(62,2)\end{array}$

Conditionnement avec Busulfan - no. (\%) $31(68,9)$

Type de donneur - no. (\%)

idique

Phéno-identique $27(60)$

Haplo-identique $2(4,4)$

$\begin{array}{ll}\text { Type de greffon - no. (\%) } & 13(28,9)\end{array}$

$\begin{array}{ll}\text { CSM } & 13(28,9) \\ \text { CSP } & 30(66,7)\end{array}$

$2(4,4)$

Prophylaxie de la GVHD - no. (\%) $3(6,7)$

Ciclosporine seule $3(6,7)$

Ciclosporine et Corticoides

$\begin{array}{ll}\text { Ciclosporine et Méthotrexate } & 16(35,6) \\ \text { Ciclosporine et Mycophénolate mofétil } & 22(48,9)\end{array}$

* Les valeurs sont exprimées en moyenne \pm écart-type, sauf mention contraire. Abréviations : LAM, Leucémie Aigüe Myéloïde; LAL, Leucémie Aigüe Lymphoïde; AREB, Anémie Réfractaire avec Excès de Blastes, CSM, Cellules Souches Mésenchymateuses; CSP, Cellules Souches Périphériques; USP, Unité de Sang Placentaire; GVHD, Graft vs Host Disease.

Tableau 3. Caractéristiques hématologiques de la population incluse dans l'étude $(n=45)$.* 


\section{RÉSULTATS}

\section{A. Sélection des patients}

Sur la période choisie de l'étude, 280 transplantations de cellules souches hématopoïétiques allogéniques ont été réalisées pour 249 patients différents. 63 patients sur 148 en réussite de greffe et non perdus de vue ont été explorés en Endocrinologie (Flowchart en Figure 1). 18 patients ne répondaient pas aux critères de sélection de l'étude. Cette étude porte donc sur 45 patients allogreffés.

La population étudiée comprend 18 hommes et 27 femmes soit un sex-ratio de 1,5.

\section{B. Données hématologiques}

Les données hématologiques des patients inclus sont présentées dans le Tableau 3.

Les patients étaient âgés de 16 à 63 ans au moment de la greffe, pour une moyenne de 45 ans. Une seule patiente était mineure, mais pubère, lors de la greffe. La répartition des âges à la greffe est la suivante (Figure 2) :

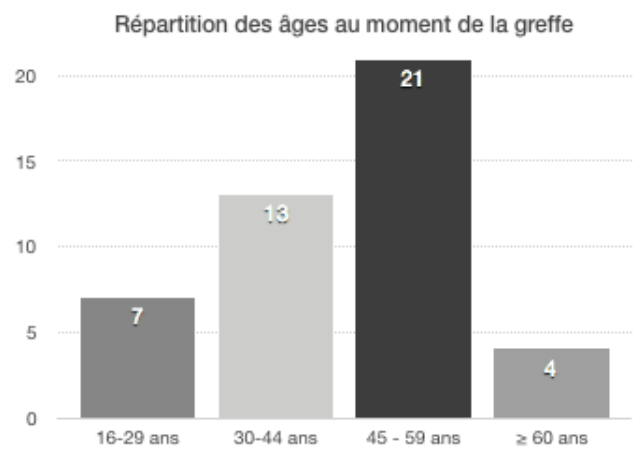

Figure 2. Répartition des âges au moment de la greffe.

Parmi les 45 patients étudiés, les pathologies hématologiques se répartissaient de la façon suivante (Figure 3 ) :

- Leucémie Aigüe Myéloïde : 26 patients,

- Leucémie Aigüe Lymphoïde : 6 patients,

- Anémie Réfractaire avec Excès de Blastes : 5 patients,

- Autres: 8 patients dont un myélome multiple, un Lymphome Hodgkinien, un Lymphome du manteau, une Leucémie tri-phénotypique, une myélofibrose primitive JAK $2+$, une LLC B atypique, une LMC et une LMMC. 


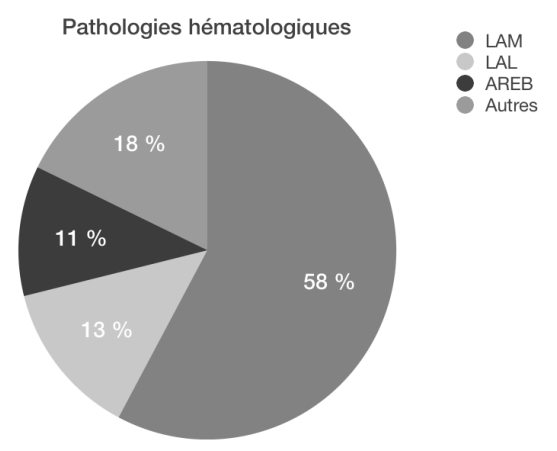

Figure 3. Répartition des pathologies hématologiques des patients inclus.

\section{Caractéristiques de la greffe}

$71,1 \%$ des patients ont été greffés dans les suites d'un traitement de leur hémopathie permettant une rémission complète.

Le conditionnement était dans $44,4 \%$ des cas myélo-ablatif, sinon d'intensité réduite.

\section{a) Conditionnement de la greffe}

L'ensemble des patients a été traité par un agent alkylant pour le conditionnement de l'allogreffe: soit par cyclophosphamide (31,1\%), soit par busulfan $(68,9 \%)$, soit par melphalan (8,9\%).

\section{(1) Irradiation Corporelle Totale}

Une Irradiation Corporelle Totale a été réalisée chez 8 patients, soit à dose de $2 \mathrm{~Gy}$ pour une allogreffe au conditionnement d'intensité réduite, soit de 8 Gy ( 3 patients) ou $12 \mathrm{~Gy}$ (4 patients) pour des allogreffes au conditionnement myélo-ablatif. L'ICT était réalisée en dose fractionnée sauf pour le patient avec l'ICT de 2 Gy.

L'ICT a été associée à une chimiothérapie chez tous les patients, comprenant :

- Du cyclophosphamide à forte dose pour les 7 conditionnements myélo-ablatif,

- Du cyclophosphamide à moindre dose et de la fludarabine pour le conditionnement d'intensité réduite.

\section{(2) Chimiothérapie seule}

Les 37 autres patients ( $82,2 \%$ de la population) ont bénéficié d'un conditionnement par chimiothérapie seule :

- 28 d'entre eux ont été traités par association de busulfan-fludarabine,

- 3 d'entre eux ont été traités par association busulfan-cyclophosphamide,

- 3 d'entre eux ont été traités par association fludarabine-cyclophosphamide,

- 3 d'entre eux ont été traités par association melphalan-clofarabine-etoposide,

- 1 d'entre eux a été traité par melphalan seul. 
Le donneur était dans (Figure 4):

- $\quad 35,6 \%$ des cas issus de la fratrie, avec une compatibilité HLA géno-identique,

- 60 \% des cas issus du fichier de donneurs volontaires de moelle osseuse, avec une compatibilité HLA la plus concordante (phéno-identique),

- 2 cas des cellules souches hématopoïétiques d'unité de sang placentaire (USP), avec une compatibilité HLA dite haplo-identique.

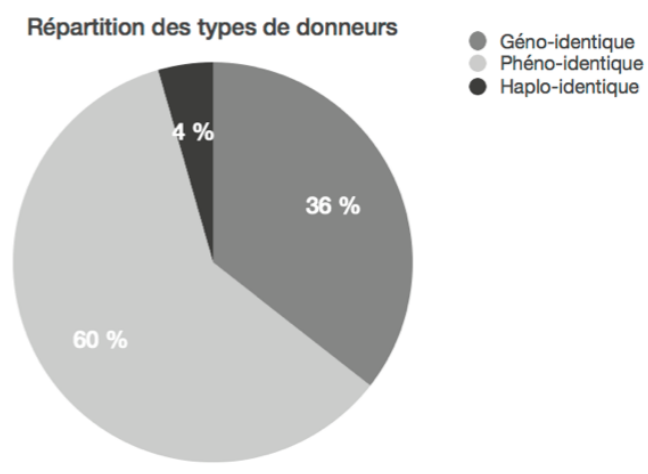

Figure 4. Répartition des types de donneurs.

Toutes les allogreffes phéno-identiques sont compatibles à 10/10 sauf deux greffes à 9/10. En prenant en compte I'HLA-DP, l'incompatibilité est de 17/27 des greffes phénoidentiques (28,3\%). Les deux allogreffes avec USP étaient incompatibles au niveau HLA à 4/6 et $5 / 6$.

Le type de greffon était dans les deux tiers des cas des cellules souches hématopoiétiques périphériques (CSP) stimulées par G-CSF, dans $28,9 \%$ des cellules souches mésenchymateuses (CSM) de moelle osseuse, et dans 2 cas des cellules souches d'USP (Figure 5).

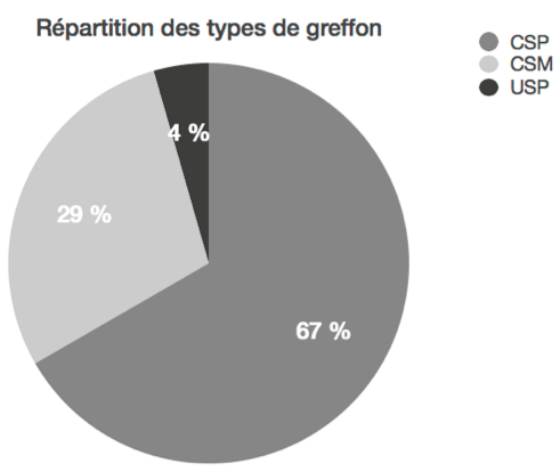

Figure 5. Répartition des types de greffon. 
Elle a comporté (Figure 6) :

- De la ciclosporine seule dans 3 cas,

- De la ciclosporine associée à une corticothérapie courte dans 3 cas,

- De la ciclosporine associée à du méthotrexate dans 16 cas,

- De la ciclosporine associée à du mycophénolate mofétil dans 22 cas,

- Un patient sans information sur la prophylaxie de la GVHD.

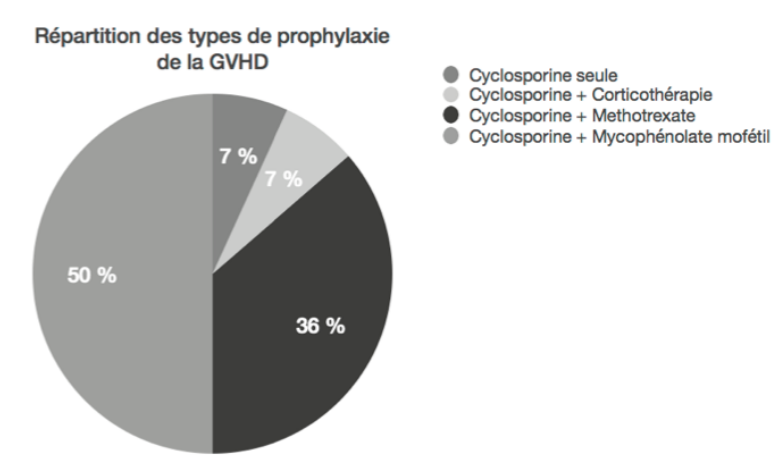

Figure 6. Répartition des types de prophylaxie de la GVHD.

2. Suite de greffe

Sur les 45 patients de l'étude, 33 patients (73,3\%) ont présenté une GVHD, qu'elle soit aigüe ou chronique.

\section{a) GVHD aigüe}

Elle est retrouvée chez 22 patients (48,9\%). Ses principales localisations sont :

- Cutanée : 19 patients,

- Buccale : 9 patients,

- Digestive : 8 patients,

- Hépatique : 1 patient,

- Génital : 1 patient.

\section{b) GVHD chronique}

Elle est retrouvée chez 19 patients (42,2 \%), dont 8 qui avaient déjà présenté une GVHD aigüe. Ses principales localisations sont :

- Cutanée : 15 patients,

- Buccale : 11 patients,

- Oculaire : 7 patients,

- Hépatique : 6 patients,

- Digestive : 2 patients,

- Génitale : 2 patients,

- Musculaire (Myosite) : 1 patient,

- Pulmonaire : 1 patient.

La GVHD chronique était légère dans 7 cas, modérée dans 6 cas et sévère dans 6 cas. 


\section{c) Corticothérapie}

Sur les 33 patients atteints de GVHD, 27 ont été traités par corticothérapie à dose supérieure à $0,8 \mathrm{mg} / \mathrm{kg} / \mathrm{j}$ d'équivalent prednisone, pour une durée moyenne de $4,2 \pm$ 4,4 mois.

La GVHD était cortico-sensible dans 20 cas et cortico-dépendante dans 7 cas. Aucun patient inclus n'avait une GVHD cortico-réfractaire.

4 autres patients ont également bénéficié d'une corticothérapie prolongée pour d'autres raisons ( 3 pour candidose hépatosplénique, 1 en association à la ciclosporine en prophylaxie prolongée de la GVHD).

Au total, 31 patients $(68,9 \%)$ des patients ont été traités par corticothérapie à forte dose pour une durée moyenne de 4,4 $\pm 4,4$ mois.

\section{Données de l'évaluation endocrinienne}

\section{Caractéristiques des patients}

Les 45 patients inclus ont été explorés dans le service d'Endocrinologie à 14,5 \pm 4,9 mois de leur greffe et avaient alors un âge moyen de 47,2 ans allant de 18 à 64 ans.

Les caractéristiques des patients inclus lors de l'exploration endocrinienne sont présentées dans le Tableau 4.

Sept patients ont été explorés avant 12 mois post-greffe (entre 9 et 11 mois) et un seul a été exploré après 24 mois post-greffe (44 mois).

Leur IMC était de $24,43 \pm 5,5 \mathrm{~kg} / \mathrm{m}^{2}$ avec $15,6 \%$ de patients en surpoids et $20 \%$ de patients obèses.

\section{Axe thyréotrope}

Une patiente de notre étude était traitée par lévothyroxine suite à une thyroïdectomie antérieure à sa pathologie hématologique. Elle a donc été exclue de nos analyses sur l'axe thyréotrope.

Sur les 44 patients, 6 présentaient une dysfonction thyroïdienne à l'évaluation endocrinienne soit $13,6 \%$ :

- 4 d'entre eux, soit 9,1 \% ont développé une hypothyroïdie périphérique, dont

2 une hypothyroïdie vraie et 2 une hypothyroïdie infraclinique,

- $\quad 2$ d'entre eux, soit 4,5\%, ont développé une insuffisance thyréotrope,

- Aucun n'a développé d'hyperthyroïdie.

Un des deux patients ayant une insuffisance thyréotrope avait bénéficié d'une ICT à $8 \mathrm{~Gy}$. 


\begin{tabular}{|c|c|}
\hline \multicolumn{2}{|l|}{ Caractéristique } \\
\hline Age à l'évaluation endocrinienne - années & $47,2 \pm 12,9$ \\
\hline Durée post-greffe à l'évaluation endocrinienne - mois & $14,5 \pm 4,9$ \\
\hline Poids - kg & $68,6 \pm 16,4$ \\
\hline Taille - cm & $1,68 \pm 0,10$ \\
\hline $\mathrm{IMC}+-\mathrm{kg} / \mathrm{m} 2$ & $24,4 \pm 5,5$ \\
\hline IMC $<20$ kg/m2 - no. (\%) & $10(22,2)$ \\
\hline IMC 20 - 25 kg/m2 - no. (\%) & $19(42,2)$ \\
\hline IMC 25 - 30 kg/m2 - no. (\%) & $7(15,6)$ \\
\hline $\mathrm{IMC}>30 \mathrm{~kg} / \mathrm{m} 2-$ no. (\%) & $9(20)$ \\
\hline \multicolumn{2}{|l|}{ Examen des anomalies lipidiques } \\
\hline Triglycérides - g/l & $1,56 \pm 0,76$ \\
\hline$H D L-g / l$ & $0,58 \pm 0,20$ \\
\hline LDL - g/l & $1,31 \pm 0,35$ \\
\hline \multicolumn{2}{|l|}{ HOMA2-IR } \\
\hline \multicolumn{2}{|l|}{ Traitement en cours - no. (\%) } \\
\hline Statines & $3(6,7)$ \\
\hline Antidiabétiques & 0 \\
\hline Immunosuppresseurs & $15(33,3)$ \\
\hline Glucocorticoïdes de synthèse & $4(8,9)$ \\
\hline Hydrocortisone & $11(24,4)$ \\
\hline Levothyroxine & $1(2,2)$ \\
\hline Hormone de Croissance & 0 \\
\hline Androgènes & 0 \\
\hline Oestro-progestatifs & $7(25,9)$ \\
\hline \multicolumn{2}{|c|}{$\begin{array}{l}\text { * Les valeurs sont exprimées en moyenne } \pm \text { écart-type, sauf mention contraire. } \\
\text { + L'IMC est le poids en kilogrammes divisé par le carré de la taille en mètres. }\end{array}$} \\
\hline \multicolumn{2}{|c|}{$\begin{array}{l}\text { Abréviations : IMC, Indice de Masse Corporelle; HDL, High-Density Lipoprotein; } \\
\text { LDL, Low-Density Lipoprotein; HOMA2-IR, Homeostasic model assessment of } \\
\text { insulin resistance version } 2 \text {. }\end{array}$} \\
\hline
\end{tabular}

Tableau 4. Caractéristiques lors de l'évaluation endocrinienne de la population incluse dans l'étude ( $n=45) .{ }^{*}$ 
Nous avons étudié la corrélation entre la survenue d'hypothyroïdie (toute cause) et différents critères suspectés d'être des facteurs de risque dans la littérature (Tableau 5). Seul l'âge $<30$ ans à la greffe est associé à une augmentation significative d'hypothyroïdie toute cause. L'Odds Ratio estimé est de 8,5 [1,3-57,2] avec un $\mathrm{P}=0,042$.

Nous avons réalisé la même analyse pour la survenue d’hypothyroïdie périphérique (Annexe 1). Nous ne retrouvons pas de caractéristiques modifiant significativement le risque de survenue de l'hypothyroïdie périphérique. L'âge $<30$ ans perd sa significativité avec un $P=0,113$.

\section{Axe corticotrope}

Trois patients n'ont pas été explorés du fait d'une corticothérapie à dose supraphysiologique en cours au moment de l'évaluation endocrinienne. Une patiente a été exclue des analyses puisque le test d'hypoglycémie insulinique réalisé n'est pas interprétable devant une chute de la glycémie insuffisante $(2,8 \mathrm{mmol} / \mathrm{l})$. Le zénith de sa cortisolémie pendant le test était de $16,6 \mu \mathrm{g} / \mathrm{dl}$.

Sur les 41 patients dont l'exploration est analysable, nous retrouvons 8 insuffisances corticotropes soit $19,5 \%$ de la population analysable :

- Chez 7 patients, le diagnostic a été établi par un test d'hypoglycémie insulinique interprétable (glycémie $<2,2 \mathrm{mmol} / \mathrm{l}$ ) avec une élévation du cortisol inférieure à $20 \mu \mathrm{g} / \mathrm{dl}$.

- Chez un patient, le diagnostic a été établi par un test au Synacthène ${ }^{\circledR} 1 \mu \mathrm{g}$ avec une élévation du cortisol à $3,7 \mu \mathrm{g} / \mathrm{dl}$ seulement.

Nous avions le résultat de l'ACTH disponible pour six de ces patients et elles étaient toutes inférieures à $10 \mathrm{pmol} / \mathrm{l}$, attestant de l'origine hypophysaire du déficit.

Sur les 8 patients, 7 patients ont été traités par corticothérapie soit pour une GVHD (5 patients pour une durée moyenne de 3,2 $\pm 1,9$ mois), soit pour une candidose hépatosplénique ( 1 patient pendant plus d'un an), soit pour une uvéite bilatérale antérieure à la greffe (1 patient pendant plusieurs années). L'un d'entre eux avait tout récemment diminué sa dose de corticothérapie à une dose de $7,5 \mathrm{mg}$ d'équivalent prednisone. Les autres avaient arrêté leur corticothérapie depuis 8,0 $\pm 4,1$ mois.

La dernière patiente n'avait ni GVHD ni corticothérapie, mais avait été traitée par ICT de 12 Gy et cyclophosphamide, au même titre qu'un des 7 patients traités pour GVHD.

Nous avons étudié la survenue d'insuffisance corticotrope selon différents critères suspectés d'être des facteurs de risque dans la littérature (Tableau 6).

Nous n'avons pas trouvé de facteur prédictif de survenue d'une insuffisance corticotrope. Les Odds Ratio pour les 3 paramètres de corticothérapie incluent la valeur de 1 (données non présentées). 
Fréquence d'Hypothyroïdie

toute cause

Valeur de $\mathbf{P}$

no./total $(\%)$

\begin{tabular}{|c|c|c|c|}
\hline \multirow[t]{2}{*}{ Sexe } & Femme & $5 / 26(19,2 \%)$ & \multirow{2}{*}{0,375} \\
\hline & Homme & $1 / 18(5,6 \%)$ & \\
\hline \multirow[t]{2}{*}{ Age à la greffe } & $<30$ ans & $3 / 7(42,9 \%)$ & \multirow{2}{*}{$0,042 *$} \\
\hline & $>30$ ans & $3 / 37(8,1 \%)$ & \\
\hline \multirow{2}{*}{ Irradiation Corporelle Totale } & Oui & $1 / 8(12,5 \%)$ & \multirow{2}{*}{1,000} \\
\hline & Non & $5 / 36(13,9 \%)$ & \\
\hline \multirow[t]{2}{*}{ Conditionnement par Busulfan } & Oui & $4 / 30(13,3 \%)$ & \multirow{2}{*}{1,000} \\
\hline & Non & $2 / 14(14,3 \%)$ & \\
\hline \multirow[t]{2}{*}{ Prophylaxie GVHD par Methotrexate } & Oui & $1 / 16(6,3 \%)$ & \multirow{2}{*}{0,392} \\
\hline & Non & $5 / 28(17,9 \%)$ & \\
\hline \multirow{2}{*}{ Prophylaxie GVHD par Mycophénolate mofétil } & Oui & $4 / 21(19,0 \%)$ & \multirow{2}{*}{0,403} \\
\hline & Non & $2 / 23(8,7 \%)$ & \\
\hline \multirow[t]{2}{*}{ Traitement par immunosuppresseur lors de l'évaluation } & Oui & $2 / 15(13,3 \%)$ & \multirow{2}{*}{1,000} \\
\hline & Non & $4 / 30(13,3 \%)$ & \\
\hline \multirow[t]{2}{*}{ GVHD aigüe } & Oui & $2 / 21(9,5 \%)$ & \multirow{2}{*}{0,666} \\
\hline & Non & $4 / 23(17,4 \%)$ & \\
\hline \multirow[t]{2}{*}{ GVHD chronique } & Oui & $4 / 19(21,1 \%)$ & \multirow{2}{*}{0,378} \\
\hline & Non & $2 / 25(8,0 \%)$ & \\
\hline \multirow[t]{2}{*}{ GVHD chronique et/ou aigüe } & Oui & $5 / 32(15,6 \%)$ & \multirow{2}{*}{1,000} \\
\hline & Non & $1 / 12(8,3 \%)$ & \\
\hline \multirow{2}{*}{ GVHD dépendante à la corticothérapie } & Oui & $1 / 7(14,3 \%)$ & \multirow{2}{*}{1,000} \\
\hline & Non & $5 / 38(13,2 \%)$ & \\
\hline \multirow[t]{2}{*}{ GVHD modérée/sévère } & Oui & $1 / 12(8,3 \%)$ & \multirow{2}{*}{1,000} \\
\hline & Non & $5 / 32(15,6 \%)$ & \\
\hline
\end{tabular}

Nombre total de patients avec données, $\mathrm{n}=44$ car une patiente exclue (thyroidectomie) A héviations : GVHD, Graft vs Host Disease.

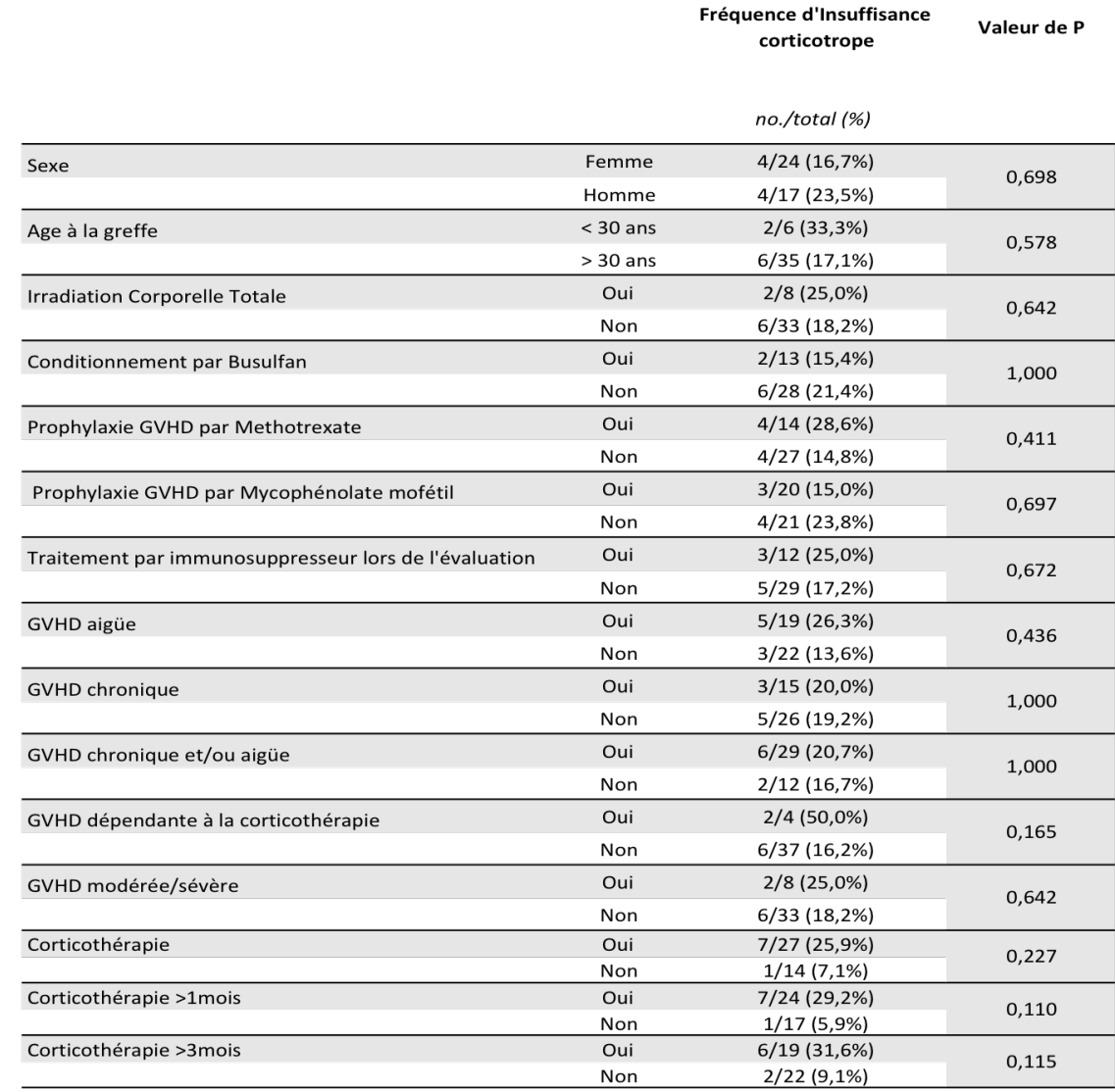

Nombre total de patients avec données, $\mathrm{n}=41$, car 3 patients non évalués et 1 patiente au résultat non-interprétable Abbréviations : GVHD, Graft vs Host Disease.

Tableau 6. Critères prédictifs de survenue d'insuffisance corticotrope.
Tableau 5. Critères prédictifs de survenue d'hypothyroïdie toute cause. 


\section{Axe somatotrope}

Deux patients ont été exclus des analyses puisque le test d'hypoglycémie insulinique réalisé n'est pas interprétable devant une chute de la glycémie insuffisante $(2,48$ et $2,8 \mathrm{mmol} / \mathrm{l})$. Le zénith de l'hormone de croissance pendant le test était respectivement de 3,6 et $10,1 \mathrm{mUl} / \mathrm{l}$.

Sur les 43 patients dont l'exploration est analysable, nous retrouvons 14 insuffisances somatotropes soit $32,6 \%$ de la population analysable :

- $5 / 14$, soit $11,6 \%$, présentent une insuffisance somatotrope sévère. Le diagnostic a été porté par un test d'hypoglycémie insulinique chez 4 d'entre eux et par un test à la GHRH-arginine chez le cinquième. Seuls deux patients avaient une IGF1 basse d'après les critères de Bidlingmaier et $a .^{53}$

- 9/14, soit $20,9 \%$, présentent une insuffisance somatotrope partielle. Le diagnostic a été porté par un test d'hypoglycémie insulinique, sauf pour un patient pour qui il a été porté par un test au Glucagon-propranolol. Seuls trois patients avaient une IGF1 basse.

Parmi les patients avec une insuffisance somatotrope, 3 avaient un IMC $<20 \mathrm{~kg} / \mathrm{m}^{2}$ et une seule avait un IMC $<18 \mathrm{~kg} / \mathrm{m}^{2}$.

Parmi les 29 patients sans insuffisance somatotrope, 6 patients avaient une IGF1 basse pour leur âge et leur sexe. Ils avaient entre 28 et 61 ans et avaient tous un IMC supérieur à $20 \mathrm{~kg} / \mathrm{m}^{2}$ (entre 22,0 et $30,8 \mathrm{~kg} / \mathrm{m} 2$ ).

Nous avons étudié la survenue d'insuffisance somatotrope selon différents critères suspectés d'être des facteurs de risque dans la littérature (Tableau 7).

Nous ne retrouvons aucun facteur prédictif de développer une insuffisance somatotrope. Le conditionnement par busulfan $(P=0,095$ et $O R=4,24[0,80-22,5])$ semble susceptible d'augmenter le risque de survenue d'insuffisance somatotrope, et la GVHD chronique modérée ou sévère $(P=0,071$ et $O R=0,15[0,017-1,28])$ de le diminuer mais sans être significatif.

L'analyse similaire du risque de survenue d'insuffisance somatotrope sévère n'a retrouvé aucun facteur de risque significatif (Annexe 2).

\section{Axe lactotrope}

Quatre patients n'ont pas eu de dosage de la prolactinémie.

Les 41 autres patients ont tous un dosage normal pour leur sexe, à l'exception d'une seule, qui avait une prolactinémie augmentée à $2200 \mathrm{mUI} / \mathrm{l}$, pour une normale inférieure à $619 \mathrm{mUl} / \mathrm{l}$. Cette hyperprolactinémie est attribuée à son traitement neuroleptique (amisulpride). 


\begin{tabular}{|c|c|c|c|}
\hline & & $\begin{array}{c}\text { Fréquence d'Insuffisance } \\
\text { somatotrope sévère et } \\
\text { modérée } \\
\text { no./total (\%) }\end{array}$ & Valeur de $\mathbf{P}$ \\
\hline \multirow[t]{2}{*}{ Sexe } & Femme & $8 / 25(32,0 \%)$ & \multirow{2}{*}{1,000} \\
\hline & Homme & $6 / 18(33,3 \%)$ & \\
\hline \multirow[t]{2}{*}{ Age à la greffe } & $<30$ ans & $2 / 7(28,6 \%)$ & \multirow{2}{*}{1,000} \\
\hline & $>30$ ans & $13 / 36(33,3 \%)$ & \\
\hline \multirow[t]{2}{*}{ IMC } & $<20 \mathrm{~kg} / \mathrm{m} 2$ & $3 / 10(30,0 \%)$ & \multirow{2}{*}{1,000} \\
\hline & $>20 \mathrm{~kg} / \mathrm{m} 2$ & $11 / 33(33,3 \%)$ & \\
\hline \multirow[t]{2}{*}{ Irradiation Corporelle Totale } & Oui & $2 / 8(25,0 \%)$ & \multirow{2}{*}{1,000} \\
\hline & Non & $12 / 35(34,3 \%)$ & \\
\hline \multirow[t]{2}{*}{ Conditionnement par Busulfan } & Oui & $12 / 29(41,4 \%)$ & \multirow{2}{*}{0,095} \\
\hline & Non & $2 / 14(14,3 \%)$ & \\
\hline \multirow[t]{2}{*}{ Prophylaxie GVHD par Methotrexate } & Oui & $5 / 16(31,3 \%)$ & \multirow{2}{*}{1,000} \\
\hline & Non & $9 / 27(33,3 \%)$ & \\
\hline \multirow[t]{2}{*}{ Prophylaxie GVHD par Mycophénolate mofétil } & Oui & $6 / 20(30,0 \%)$ & \multirow{2}{*}{1,000} \\
\hline & Non & $8 / 12(34,8 \%)$ & \\
\hline \multirow[t]{2}{*}{ Traitement par immunosuppresseur lors de l'évaluation } & Oui & $5 / 15(33,3 \%)$ & \multirow{2}{*}{1,000} \\
\hline & Non & $9 / 28(32,1 \%)$ & \\
\hline \multirow[t]{2}{*}{ GVHD aigüe } & Oui & $8 / 21(38,1 \%)$ & \multirow{2}{*}{0,526} \\
\hline & Non & $6 / 22(27,3 \%)$ & \\
\hline \multirow[t]{2}{*}{ GVHD chronique } & Oui & $4 / 17(23,5 \%)$ & \multirow{2}{*}{0,343} \\
\hline & Non & $10 / 26(38,5 \%)$ & \\
\hline \multirow[t]{2}{*}{ GVHD chronique et/ou aigüe } & Oui & $10 / 31(32,3 \%)$ & \multirow{2}{*}{1,000} \\
\hline & Non & $4 / 12(33,3 \%)$ & \\
\hline \multirow[t]{2}{*}{ GVHD dépendante à la corticothérapie } & Oui & $1 / 6(16,7 \%)$ & \multirow{2}{*}{0,645} \\
\hline & Non & $13 / 37(35,1 \%)$ & \\
\hline \multirow[t]{2}{*}{ GVHD modérée/sévère } & Oui & $1 / 11(9,1 \%)$ & \multirow{2}{*}{0,071} \\
\hline & Non & $13 / 32(40,6 \%)$ & \\
\hline
\end{tabular}

$\S$ Nombre total de patients avec données, $n=43$, car 2 patients aux résultats non-interprétables Abbréviations : IMC, Indice de Masse Corporelle; GVHD, Graft vs Host Disease.

Tableau 7. Critères prédictifs de survenue d'insuffisance somatotrope (sévère et modérée). ${ }^{\S}$ 
6. Axe gonadotrope

a) Chez les femmes

Sur les 27 femmes de notre étude, 11 étaient ménopausées avant le diagnostic deleur hémopathie. Aucune n'avait de traitement substitutif lors de l'exploration endocrinienne. Toutes ces femmes avaient un profil gonadique en faveur d'une ménopause devant une FSH élevée (entre 28 et $142 \mathrm{UI} / \mathrm{I}$ ) et une estradiolémie indosable. Deux avaient bénéficié d'une ICT.

Sur les 16 femmes non-ménopausées avant le diagnostic de leur pathologie :

- 7 patientes avaient une substitution estrogénique dont une par contraception estroprogestative.

- La patiente sous contraception estroprogestative, lors de l'évaluation endocrinienne, avait une FSH effondrée en rapport avec une inhibition de l'axe gonadotrope par sa contraception estroprogestative. Une patiente sous traitement hormonal substitutif lors de l'évaluation endocrinienne présentait une FSH basse à 4,6 UI/I. Pour ces deux patientes, leur FSH était augmentée lors d'un dosage antérieur à l'instauration du traitement, témoin d'une insuffisance ovarienne primitive.

- Les 5 autres patientes avaient une FSH élevée entre 40 et $101 \mathrm{UI} / \mathrm{I}$.

- Les 12 patientes sans traitement substitutif avaient toutes une FSH élevée (entre 67 et $127 \mathrm{UI} / \mathrm{I}$ ) en association à une estradiolémie basse et étaient en aménorrhée.

- Sur ces 16 patientes, cinq avaient bénéficié d'une ICT. Sur les 11 femmes qui n'ont pas reçu d'ICT, 9 ont été traitées par busulfanfludarabine, une par busulfan-cyclophosphamide et une par fludarabinecyclophosphamide. 7 patientes ont reçu un conditionnement d'intensité réduite.

Par ailleurs, 14 femmes ont eu un conditionnement d'intensité réduite.

Au total, aucune patiente n'a de fonction gonadique préservée après son allogreffe. Toutes sont en ménopause ou en insuffisance ovarienne primitive avec des gonadotrophines élevées. Aucune patiente n'a de déficit hypophysaire en gonadotrophines.

\section{b) Chez les hommes}

\section{(1) Troubles de la spermatogenèse}

Sur les 18 hommes de l'étude, 9 avaient une FSH élevée (> 18,1 UI/I) entre 19 et $32 \mathrm{UI} / \mathrm{l}$ au moment de l'exploration endocrinienne. Aucun d'entre eux n'avait de FSH abaissée pouvant faire suspecter une atteinte centrale.

Un des patients, avec une FSH à $19 \mathrm{UI} / \mathrm{l}$, avait réalisé un spermogramme 4 mois avant l'évaluation hormonale qui montrait une azoospermie. Son inhibine $B$ était dans la norme inférieure à $18,1 \mathrm{ng} / \mathrm{l}$ (normale entre $11,5-368,9 \mathrm{ng} / \mathrm{l}$ ). 
L'étude des critères prédictifs de survenue d'une élévation de la FSH ne dégage aucun facteur de risque (Tableau 8). Nous n'avons retrouvé aucun facteur prédictif de survenue d'une élévation de la FSH chez l'homme.

\section{(2) Hypogonadisme masculin}

Un seul patient avait un hypogonadisme caractérisé par une diminution de la testostéronémie $(2,83 \mathrm{ng} / \mathrm{ml}$, pour une norme entre $3-12 \mathrm{ng} / \mathrm{ml})$. Sa LH en regard était non-augmentée à $9,2 \mathrm{UI} / \mathrm{l}$, témoin d'un hypogonadisme central ou hypogonadotrophique. II n'a pas bénéficié d'ICT mais un conditionnement d'intensité réduite par busulfan-fludarabine et a eu une GVHD aigüe digestive grade 2, cortico-sensible. L'ensemble des autres patients avait un taux de testostérone normal, en moyenne à 5,49 \pm $1,85 \mathrm{ng} / \mathrm{ml}$.

Cinq patients avaient une LH augmentée (entre 10 et $33 \mathrm{UI} / \mathrm{I}$ ) sans baisse de la testostérone. Cette élévation de la LH peut être attribuée à un hypogonadisme hypergonadotrophique (ou testiculaire) débutant, bien compensé. Ils n'ont pas été traités par ICT. 3 ont eu un conditionnement par busulfan-fludarabine et 2 par cyclophosphamidefludarabine.

\section{Conséquences osseuses}

43 patients ont bénéficié d'une ostéodensitométrie. 33 d'entre eux ont une diminution de leur densité minérale osseuse soit $76,7 \%$ de la population analysable.

- 12 d'entre eux avaient une ostéoporose, soit 27,9 \%. 5 avaient une ostéoporose fémorale et lombaire, 5 une ostéoporose vertébrale et 2 une ostéoporose fémorale.

- 21 d'entre eux avaient une ostéopénie, soit 48,8 \%. 10 avaient une ostéopénie fémorale et lombaire, 7 une ostéopénie vertébrale et 4 une ostéopénie fémorale.

Concernant les 11 femmes ménopausées avant le diagnostic de l'hémopathie, $54 \%$ (6) avaient une ostéoporose et 4 une ostéopénie, correspondant à une baisse de la DMO (Densité Minérale Osseuse) dans $90 \%$ des cas.

Aucun patient n'a présenté d'ostéonécrose avasculaire.

Concernant le taux de vitamine $D$, les trois quarts des patients n'avaient pas un taux suffisant. La carence était profonde chez $18 \%$ et modérée chez $57 \%$ d'entre eux.

Nous avons étudié la corrélation entre la diminution de la DMO ou l'ostéoporose et différents critères suspectés d'être des facteurs de risque dans la littérature (Tableau 9).

Le conditionnement par busulfan est associé significativement à une protection de la DMO. L'Odds Ratio estimé est de 0,66 [0,50 - 0,85] avec un $P=0,018$. Un IMC $<20 \mathrm{~kg} / \mathrm{m}^{2}$ et une insuffisance somatotrope semble être associé à une déminéralisation osseuse, sans pour autant être significatif $(P=0,084$ et $P=0,064)$.

Un âge $\geq 50$ ans est corrélé à une augmentation de l'ostéoporose avec un Odds Ratio estimé à $12,2[2,2-67,2]$ et un $P=0,002$. Une carence profonde en vitamine $D$ est associée à une majoration de l'ostéoporose avec un Odds Ratio estimé à 5,95 [1,13 - 31,26] et un $\mathrm{P}=0,039$. 


\begin{tabular}{|c|c|c|c|}
\hline & & $\begin{array}{c}\text { Fréquence d'élévation de } \\
\text { la FSH masculine } \\
\text { no./total (\%) }\end{array}$ & Valeur de $\mathbf{P}$ \\
\hline \multirow[t]{2}{*}{ Age à la greffe } & $<30$ ans & $2 / 3(66,7 \%)$ & \multirow{2}{*}{1,000} \\
\hline & $>30$ ans & $7 / 15(46,7 \%)$ & \\
\hline \multirow[t]{2}{*}{ Irradiation Corporelle Totale } & Oui & $0 / 1(0,0 \%)$ & \multirow{2}{*}{1,000} \\
\hline & Non & $9 / 17(52,9 \%)$ & \\
\hline \multirow[t]{2}{*}{ Conditionnement par Busulfan } & Oui & $6 / 13(46,2 \%)$ & \multirow{2}{*}{1,000} \\
\hline & Non & $3 / 5(60,0 \%)$ & \\
\hline \multirow[t]{2}{*}{ Conditionnement Myélo-ablatif } & Oui & $4 / 7(57,1 \%)$ & \multirow{2}{*}{1,000} \\
\hline & Non & $5 / 11(45,5 \%)$ & \\
\hline \multirow[t]{2}{*}{ Prophylaxie GVHD par Methotrexate } & Oui & $3 / 8(37,5 \%)$ & \multirow{2}{*}{0,637} \\
\hline & Non & $6 / 10(60,0 \%)$ & \\
\hline \multirow[t]{2}{*}{ Prophylaxie GVHD par Mycophénolate mofétil } & Oui & $5 / 9(55,6 \%)$ & \multirow{2}{*}{1,000} \\
\hline & Non & $4 / 9(44,4 \%)$ & \\
\hline \multirow[t]{2}{*}{ Traitement par immunosuppresseur lors de l'évaluation } & Oui & $3 / 6(50,0 \%)$ & \multirow{2}{*}{1,000} \\
\hline & Non & $6 / 12(50,0 \%)$ & \\
\hline \multirow[t]{2}{*}{ GVHD aigüe } & Oui & $6 / 11(54,5 \%)$ & \multirow{2}{*}{1,000} \\
\hline & Non & $3 / 7(42,9 \%)$ & \\
\hline \multirow[t]{2}{*}{ GVHD chronique } & Oui & $2 / 5(40,0 \%)$ & \multirow{2}{*}{1,000} \\
\hline & Non & $7 / 13(53,8 \%)$ & \\
\hline \multirow[t]{2}{*}{ GVHD chronique et/ou aigüe } & Oui & $7 / 15(46,7 \%)$ & \multirow{2}{*}{1,000} \\
\hline & Non & $2 / 3(66,7 \%)$ & \\
\hline \multirow[t]{2}{*}{ GVHD dépendante à la corticothérapie } & Oui & $2 / 2(100,0 \%)$ & \multirow{2}{*}{0,471} \\
\hline & Non & $7 / 16(43,8 \%)$ & \\
\hline \multirow[t]{2}{*}{ GVHD modérée/sévère } & Oui & $1 / 3(33,3 \%)$ & \multirow{2}{*}{1,000} \\
\hline & Non & $8 / 15(53,3 \%)$ & \\
\hline
\end{tabular}

Nombre total de patients avec données, $\mathrm{n}=18$

Abbréviations : FSH, Follicle Stimulating Hormone; GVHD, Graft vs Host Disease.

Tableau 8. Critères prédictifs d'élévation de la FSH chez l'homme. 


\begin{tabular}{|c|c|c|c|c|c|}
\hline & & $\begin{array}{c}\text { Fréquence de DMO basse } \\
\text { no./total (\%) }\end{array}$ & Valeur de $\mathbf{P}$ & $\begin{array}{c}\text { Fréquence d'ostéoporose } \\
\text { no./total (\%) }\end{array}$ & Valeur de $\mathrm{P}$ \\
\hline \multirow[t]{2}{*}{ Sexe } & Femme & $21 / 27(77,8 \%)$ & \multirow{2}{*}{1,000} & $8 / 27(29,6 \%)$ & \multirow{2}{*}{1,000} \\
\hline & Homme & $12 / 16(75,0 \%)$ & & $4 / 16(25,0 \%)$ & \\
\hline \multirow[t]{2}{*}{ Age à la greffe } & $<30$ ans & $4 / 7(57,1 \%)$ & \multirow{2}{*}{0,325} & $0 / 7(0,0 \%)$ & \multirow{2}{*}{0,163} \\
\hline & $>30$ ans & $29 / 36(80,6 \%)$ & & $12 / 36(33,3 \%)$ & \\
\hline \multirow[t]{2}{*}{ Age à la greffe } & $<50$ ans & $18 / 24(75,0 \%)$ & \multirow{2}{*}{1,000} & $2 / 24(8,3 \%)$ & \multirow{2}{*}{$0,002^{* *}$} \\
\hline & $\geq 50$ ans & $15 / 19(78,9 \%)$ & & $10 / 19(52,6 \%)$ & \\
\hline \multirow[t]{2}{*}{$\mathrm{IMC}<20 \mathrm{~kg} / \mathrm{m} 2$} & Oui & $10 / 10(100,0 \%)$ & \multirow{2}{*}{0,084} & $3 / 10(30,0 \%)$ & \multirow{2}{*}{1,000} \\
\hline & Non & $23 / 33(69,7 \%)$ & & $9 / 33(27,3 \%)$ & \\
\hline \multirow[t]{2}{*}{ LAL } & LAL & $6 / 6(100,0 \%)$ & \multirow{2}{*}{0,309} & $1 / 6(16,7 \%)$ & \multirow{2}{*}{0,659} \\
\hline & Autres & $27 / 37(73,0 \%)$ & & $11 / 37(29,7 \%)$ & \\
\hline \multirow[t]{2}{*}{ Irradiation Corporelle Totale } & Oui & $8 / 8(100,0 \%)$ & \multirow{2}{*}{0,165} & $2 / 8(25,0 \%)$ & \multirow{2}{*}{1,000} \\
\hline & Non & $25 / 35(71,4 \%)$ & & $10 / 35(28,6 \%)$ & \\
\hline \multirow[t]{2}{*}{ Conditionnement par Busulfan } & Oui & $19 / 29(65,5 \%)$ & \multirow{2}{*}{$0,018 *$} & $9 / 29(31,0 \%)$ & \multirow{2}{*}{0,720} \\
\hline & Non & $14 / 14(100,0 \%)$ & & $3 / 14(21,4 \%)$ & \\
\hline \multirow[t]{2}{*}{ Prophylaxie GVHD par Methotrexate } & Oui & $13 / 16(81,3 \%)$ & \multirow{2}{*}{0,719} & $5 / 16(31,3 \%)$ & \multirow{2}{*}{0,737} \\
\hline & Non & $20 / 27(74,1 \%)$ & & $7 / 27(25,9 \%)$ & \\
\hline Prophylaxie GVHD par Mycophénolate mofétil & Oui & $15 / 20(75,0 \%)$ & 1000 & $6 / 22(30,0 \%)$ & 1000 \\
\hline & Non & $18 / 23(78,3 \%)$ & $1,0 \cup 0$ & $6 / 23(26,1 \%)$ & 1,000 \\
\hline Traitement par immunosuppresseur lors de l'évaluation & Oui & $12 / 15(80,0 \%)$ & 1000 & $4 / 15(26,7 \%)$ & 1000 \\
\hline & Non & $21 / 28(75,0 \%)$ & 1,000 & $8 / 28(28,6 \%)$ & \\
\hline GVHD aigüe & Oui & $17 / 21(81,0 \%)$ & 0721 & $8 / 21(38,1 \%)$ & 0185 \\
\hline & Non & $16 / 22(72,7 \%)$ & $0,1<1$ & $4 / 22(18,2 \%)$ & , \\
\hline GVHD chronique & Oui & $14 / 18(77,8 \%)$ & 1000 & $7 / 18(38,9 \%)$ & 0301 \\
\hline & Non & $19 / 25(76,0 \%)$ & & $5 / 25(20,0 \%)$ & \\
\hline GVHD chronique et/ou aigüe & Oui & $24 / 31(77,4 \%)$ & 1000 & $10 / 31(32,3 \%)$ & 0956 \\
\hline & Non & $9 / 12(75,0 \%)$ & 1,000 & $2 / 12(16,7 \%)$ & \\
\hline GVHD résistante à la corticothérapie & Oui & $5 / 7(71,4 \%)$ & 0.656 & $3 / 7(42,9 \%)$ & 0.378 \\
\hline & Non & $28 / 36(77,8 \%)$ & 0,030 & $9 / 36(25,0 \%)$ & \\
\hline GVHD modérée/sévère & Oui & $8 / 11(72,7 \%)$ & 0698 & $4 / 11(36,4 \%)$ & 0467 \\
\hline & Non & $25 / 32(78,1 \%)$ & 0,050 & $8 / 32(25,0 \%)$ & \\
\hline Insuffisance Somatotrope (modérée et sévère) & Oui & $8 / 14(57,1 \%)$ & م064 & $5 / 14(35,7 \%)$ & (267 \\
\hline & Non & $23 / 37(85,2 \%)$ & 0,064 & $5 / 27(18,5 \%)$ & $0, \angle b /$ \\
\hline Insuffisance Somatotrope sévère & Oui & $3 / 5(60,0 \%)$ & 0580 & $3 / 5(60,0 \%)$ & 0083 \\
\hline & Non & $28 / 36(77,8 \%)$ & 0,580 & $7 / 36(19,4 \%)$ & , 083 \\
\hline Hypothyroïdie (toute cause) & Oui & $5 / 6(83,3 \%)$ & 1000 & $1 / 6(16,7 \%)$ & 1000 \\
\hline & Non & $27 / 36(75,0 \%)$ & & $10 / 36(27,8 \%)$ & \\
\hline Corticothérapie & Oui & $22 / 29(75,9 \%)$ & 100 & $9 / 29(31,0 \%)$ & חברד 0 \\
\hline & Non & $11 / 14(78,6 \%)$ & 1,000 & $3 / 14(21,4 \%)$ & $0,1<0$ \\
\hline Corticothérapie $>1$ mois & Oui & $21 / 26(80,8 \%)$ & 0481 & $9 / 26(34,6 \%)$ & 0336 \\
\hline & Non & $12 / 17(70,6 \%)$ & 0,481 & $3 / 17(17,6 \%)$ & , 300 \\
\hline Corticothérapie $>3$ mois & Oui & $17 / 21(81,0 \%)$ & 1 & $8 / 21(38,1 \%)$ & 0185 \\
\hline & Non & $16 / 22(72,7 \%)$ & & $4 / 22(18,2 \%)$ & \\
\hline Déficit en vitamine $D$ profond & Oui & $7 / 8(87,5 \%)$ & 0655 & $5 / 8(62,5 \%)$ & ก $039 *$ \\
\hline & Non & $24 / 32(75,0 \%)$ & 0,0כנ & $7 / 32(21,9 \%)$ & \\
\hline
\end{tabular}

Nombre total de patients avec données, $\mathrm{n}=43$, car 2 patients n'ont pas réalisé d'ostéodensitométrie

Abbréviations : DMO, Densité Minérale Osseuse; LAL, Leucémie Aigüe Lymphoïde; GVHD, Graft vs Host Disease.

Tableau 9. Critères prédictifs de diminution de la DMO et de l'ostéoporose. 


\section{Conséquences métaboliques}

En moyenne, les patients avaient un examen des anomalies lipidiques dans la norme du laboratoire du CHRU de Brest soit 1,56 $\pm 0,76 \mathrm{~g} / \mathrm{l}$ de Triglycérides, 0,58 $\pm 0,20 \mathrm{~g} / \mathrm{l}$ d'HDL et $1,31 \pm 0,35 \mathrm{~g} / \mathrm{I}$ de LDLc. A noter que trois patients ont été évalués sous traitement par statines. Parmi l'ensemble de la population incluse, $45,5 \%$ avaient une dyslipidémie (20/44) dont :

- 14 patients $(31,8 \%)$ avaient une hypertriglycéridémie $>1,77 \mathrm{~g} / \mathrm{l}$, allant jusqu'à $3,6 \mathrm{~g} / \mathrm{l}$,

- 13 patients (29,5\%) un HDL $\leq 0,39 \mathrm{~g} / \mathrm{L}$ pour les hommes (4 hommes/18) ou $\leq 0,50 \mathrm{~g} / \mathrm{L}$ pour les femmes ( 9 femmes/27),

- Un patient avait un LDLc $>1,9 \mathrm{~g} / \mathrm{l}$ et deux avaient un LDL incalculable devant une hypertriglycéridémie $>3,4 \mathrm{~g} / \mathrm{l}$.

Parmi les 14 patients avec une hypertriglycéridémie, 6 patients avaient un IMC compris entre 20 et $25 \mathrm{~kg} / \mathrm{m}^{2}$. Parmi les 13 patients avec un HDL abaissé, 8 avaient un IMC compris entre 20 et $25 \mathrm{~kg} / \mathrm{m}^{2}$. Au total, sur les 20 patients avec dyslipidémie, 11 ont un IMC normal.

Aucun des patients n'avait de traitements antidiabétiques, mais deux patients présentaient un antécédent de diabète cortico-induit. La glycémie à jeun était en moyenne de $0,88 \pm 0,10 \mathrm{~g} / \mathrm{l}$ allant de 0,7 à $1,15 \mathrm{~g} / \mathrm{l}$. 8 patients avaient une glycémie $\geq 1 \mathrm{~g} / \mathrm{l}(17,8 \%)$ et 2 une hyperglycémie modérée à jeun $\geq 1,1 \mathrm{~g} / \mathrm{l}$.

Le nombre de patients avec une insulino-résistance estimée par un HOMA2-IR $\geq 1,21$ était de 8 , soit $17,8 \%$ de la population de l'étude. Ils avaient tous un IMC $>25 \mathrm{~kg} / \mathrm{m}^{2}$ et le sexratio était de 1 . Concernant les marqueurs biologiques du syndrome métabolique, 3 d'entre eux avaient une hypertriglycéridémie isolée, une patiente avait un HDL bas isolé, et deux une glycémie $\geq 1 \mathrm{~g} / \mathrm{l}$ isolé.

Nous avons étudié la corrélation entre I'HOMA2-IR et différents critères connus ou suspectés d'être des facteurs de risque d'insulino-résistance. Les données sont présentées dans le Tableau 10.

L'IMC $>25 \mathrm{~kg} / \mathrm{m} 2$, le conditionnement par busulfan et la prophylaxie par mycophénolate mofétil sont associés à une augmentation de l'insulino-résistance. Une prophylaxie par méthotrexate est associée à une diminution de l'insulino-résistance. 
moyenne \pm écart-type

\begin{tabular}{|c|c|c|c|}
\hline \multirow{3}{*}{ Sexe } & \\
\hline & Femme & $0,79 \pm 0,60$ & \multirow{2}{*}{0,309} \\
\hline & Homme & $1,20 \pm 1,55$ & \\
\hline \multirow[t]{2}{*}{ Age à la greffe } & $<30$ ans & $0,86 \pm 0,64$ & \multirow{2}{*}{0,779} \\
\hline & $>30$ ans & $0,97 \pm 1,15$ & \\
\hline \multirow{2}{*}{$\mathrm{IMC}>25 \mathrm{~kg} / \mathrm{m} 2$} & Oui & $1,62 \pm 1,57$ & \multirow{2}{*}{$0,0001 * * *$} \\
\hline & Non & $0,56 \pm 0,21$ & \\
\hline \multirow[t]{2}{*}{ Traitement par immunosuppresseur lors de l'évaluation } & Oui & $0,67 \pm 0,39$ & \multirow{2}{*}{0,207} \\
\hline & Non & $1,10 \pm 1,29$ & \\
\hline \multirow[t]{2}{*}{ Conditionnement par Busulfan } & Oui & $1,18 \pm 1,28$ & \multirow{2}{*}{$0,010 *$} \\
\hline & Non & $0,52 \pm 0,15$ & \\
\hline \multirow[t]{2}{*}{ Prophylaxie GVHD par Methotrexate } & Oui & $0,67 \pm 0,68$ & \multirow{2}{*}{$0,024 *$} \\
\hline & Non & $1,08 \pm 1,21$ & \\
\hline \multirow[t]{2}{*}{ Prophylaxie GVHD par Mycophénolate mofétil } & Oui & $1,29 \pm 1,37$ & \multirow{2}{*}{$0,001 * *$} \\
\hline & Non & $0,62 \pm 0,54$ & \\
\hline \multirow[t]{2}{*}{ GVHD chronique } & Oui & $0,76 \pm 0,63$ & \multirow{2}{*}{0,269} \\
\hline & Non & $1,08 \pm 1,29$ & \\
\hline \multirow[t]{2}{*}{ GVHD aigüe } & Oui & $0,79 \pm 0,42$ & \multirow{2}{*}{0,813} \\
\hline & Non & $1,17 \pm 1,60$ & \\
\hline \multirow[t]{2}{*}{ GVHD chronique et/ou aigüe } & Oui & $0,82 \pm 0,54$ & \multirow{2}{*}{0,945} \\
\hline & Non & $1,38 \pm 2,02$ & \\
\hline \multirow[t]{2}{*}{ GVHD dépendante à la corticothérapie } & Oui & $0,78 \pm 0,37$ & \multirow{2}{*}{0,936} \\
\hline & Non & $0,99 \pm 1,17$ & \\
\hline \multirow[t]{2}{*}{ GVHD modérée/sévère } & Oui & $0,85 \pm 0,71$ & \multirow{2}{*}{0,910} \\
\hline & Non & $1,00 \pm 1,21$ & \\
\hline \multirow[t]{2}{*}{ Insuffisance Somatotrope } & Oui & $0,81 \pm 0,54$ & \multirow{2}{*}{0,801} \\
\hline & Non & $1,02 \pm 1,26$ & \\
\hline \multirow[t]{2}{*}{ Insuffisance Somatotrope sévère } & Oui & $0,66 \pm 0,45$ & בר 0 \\
\hline & Non & $1,00 \pm 1,14$ & $0,3 / 2$ \\
\hline Hypothyroïdie (toute cause) & Oui & $1,02 \pm 0,64$ & 0362 \\
\hline & Non & $0,94 \pm 1,14$ & 0,362 \\
\hline Hypothyroïdie (périph/infraclinique) & Oui & $1,02 \pm 0,64$ & 0.253 \\
\hline & Non & $0,94 \pm 1,14$ & 0,253 \\
\hline Corticothérapie & Oui & $1,04 \pm 1,22$ & 0.407 \\
\hline & Non & $0,72 \pm 0,48$ & 0,407 \\
\hline Corticothérapie $>1$ mois & Oui & $1,04 \pm 1,26$ & 0.626 \\
\hline & Non & $0,77 \pm 0,50$ & \\
\hline Corticothérapie $>3$ mois & Oui & $1,09 \pm 1,39$ & 0681 \\
\hline & Non & $0,79 \pm 0,49$ & 0,001 \\
\hline
\end{tabular}

Nombre total de patients avec données, $\mathrm{n}=38$ car 7 patients sans dosage de l'insulinémie.

Abbréviations : HOMA2-IR, Homeostasis Model Assessment-Insuline Resistance ; IMC, Indice de Masse Corporelle; GVHD, Graft vs Host Disease.

Tableau 10. Comparaison de I'HOMA2-IR selon différents critères. 


\section{Insuffisance antéhypophysaire}

L'insuffisance antéhypophysaire est définie par un déficit d'au moins un des axes antéhypophysaires.

20 patients correspondent à cette définition soit $44,4 \%$ de notre population :

- 15 ont un déficit d'un seul axe (10 insuffisances somatotropes, 3 insuffisances corticotropes, une insuffisance gonadotrope et une insuffisance thyréotrope), soit $31,1 \%$ de la population,

- 5 ont un déficit de deux axes hypophysaires (4 ont un déficit somatotrope et corticotrope, une a un déficit thyréotrope et corticotrope) soit $11,1 \%$ de la population,

- Aucun ne présente d'insuffisance antéhypophysaire globale.

Ces patients ont tous été conditionnés par busulfan-fludarabine sauf 4 patients par cyclophosphamide-ICT ( 8 ou $12 \mathrm{~Gy}$ ) (un insuffisant somato-corticotrope, un insuffisant thyréo-corticotrope, un insuffisant somatotrope, et un insuffisant thyréotrope) et un patient par busulfan-cyclophosphamide (insuffisant somatotrope). 


\section{DISCUSSION}

\section{A. Résultats principaux}

Notre étude a été réalisée sur une population de 45 patients âgés de 47,2 ans en moyenne, à 14,5 mois de moyenne d'une transplantation de cellules souches hématopoïétiques allogéniques. Nos résultats montrent de nombreuses altérations endocriniennes et métaboliques. Les principaux résultats illustrant les caractéristiques de notre population sont les suivants :

- Axe thyréotrope : 13,6 \% (6/44) des patients ont une dysfonction thyroïdienne: $9,1 \%(4 / 44)$ une hypothyroïdie périphérique et $4,5 \%(2 / 44)$ une hypothyroïdie centrale.

- Axe corticotrope: $19,5 \%(8 / 41)$ des patients ont une insuffisance corticotrope avérée.

- Axe somatotrope : 32,6 \% (14/43) des patients ont une insuffisance somatotrope : $11,6 \%(5 / 43)$ d'insuffisance somatotrope sévère et 20,6 \% (9/43) d'insuffisance partielle.

- Axe gonadotrope :

○ Chez la femme: $100 \%$ (16/16) des femmes non-ménopausées avant le diagnostic de leur hémopathie présentent une insuffisance ovarienne primitive. Sur l'ensemble des femmes, aucune n'a d'insuffisance gonadotrope.

- Chez l'homme: $50 \%$ (9/18) des hommes ont une FSH élevée suggérant une atteinte de la spermatogenèse. $27,8 \%$ des hommes $(5 / 18)$ ont un hypogonadisme hypergonadotrophique compensé. Un patient présente un hypogonadisme central hypogonadotrophique avec une testostérone abaissée $(5,5 \%, 1 / 18)$.

- Insuffisance antéhypophysaire: 42,2 \% (19/45) des patients présentent un ou plusieurs déficits antéhypophysaires.

- Conséquences osseuses: $76,7 \%$ des patients ont une diminution de la densité minérale osseuse, soit une ostéopénie $(48,8 \%)$ soit une ostéoporose $(27,9 \%)$.

- Conséquences métaboliques :

○ $20 \%$ des patients sont obèses,

○ 44,4 \% (20/45) ont une dyslipidémie dont 31,1\% (14/45) une hypertriglycéridémie,

○ 4,4 \% (2/45) ont une glycémie $\geq 1,1 \mathrm{~g} / \mathrm{l}$ témoin d'une hyperglycémie modérée à jeun, et deux ont eu un diabète cortico-induit,

○ $17,8 \%$ (8/45) ont un HOMA-IR élevé, témoin d'une insulino-résistance. 


\section{B. Axe thyréotrope}

Dans notre population, nous retrouvons 13,6 \% d'hypothyroïdie comprenant $1 / 3$ d'hypothyroïdie périphérique vraie, $1 / 3$ d'hypothyroïdie infraclinique et $1 / 3$ d'insuffisance thyréotrope.

Nos résultats sont concordants avec ceux des études réalisées chez l'adulte $(0$ à $8 \%$ d'hypothyroïdie vraie, jusqu'à $28,7 \%$ d'hypothyroïdie infraclinique, et jusqu'à $5 \%$ d'insuffisance thyréotrope).

Seul l'âge inférieur à 30 ans est un critère prédictif de survenue d'hypothyroïdie dans notre étude. Ce critère avait déjà été remarqué par plusieurs études, ${ }^{6,8,9}$ mais pour un âge inférieur à 9 ou 10 ans dans des populations pédiatriques. Ces mêmes auteurs précisent que la thyroïde est plus sensible au traitement cytotoxique jusqu'à un âge de 20 ans, ce qui va dans le sens de nos résultats.

En revanche, I'ICT n'est pas un facteur de risque d'hypothyroïdie dans notre étude avec une proportion quasiment identique d'hypothyroïdie toute cause ou périphérique dans les deux groupes (irradié ou non). Néanmoins, le risque d'hypothyroïdie périphérique postirradiation a surtout été étudié dans des populations pédiatriques et souvent à de fortes doses non-fractionnées. D'après Sklar et al., le risque d'hypothyroïdie périphérique commence dès $10 \mathrm{~Gy}$ d'irradiation et est proportionnel à la dose. ${ }^{10}$ Notre population a été irradiée à de plus faibles doses (<12 Gy) que dans les études pédiatriques (18 Gy en moyenne pour l'étude Berger et $a l^{8}{ }^{8}$ et jusqu'à 15,75 Gy dans l'étude de Sanders et $a l^{6}{ }^{6}$ ) et à des doses fractionnées.

Deux études réalisées chez l'adulte (Littley et al. et Kauppila et $a l$. $)^{35,36}$ retrouvaient également I'ICT comme facteur de risque d'hypothyroïdie pour des doses d'irradiation similaires aux nôtres et à doses fractionnées. Cette différence pourrait s'expliquer par une exploration post-greffe plus rapprochée dans notre étude, en moyenne à 14,5 mois en comparaison des autres études ( $>17$ mois pour Littley et al. et 38 mois en moyenne pour Kauppila et al.). Par ailleurs, I'ICT chez l'enfant est responsable d'hypothyroïdie généralement après 4 ans, ${ }^{29}$ ce qui souligne notre hypothèse.

Le sexe n'est pas un critère prédictif de survenue des dysthyroïdie dans notre étude, ceux qui va à l'encontre des résultats de l'étude pédiatrique de Sklar, ${ }^{10}$ mais concordante avec les études réalisées chez l'adulte. ${ }^{34-39}$ De fait, nous aurions pu nous attendre à une augmentation d'hypothyroïdie périphérique chez les femmes, comme il est reconnu dans la population adulte.

Savani et al., dans une population mixte d'enfants et adultes (6-66 ans), avaient retrouvé une fréquence d'hypothyroïdie périphérique augmentée chez les patients atteints d'une GVHD prolongée. ${ }^{54}$ Notre recueil de données ne comprenait pas la durée de la GVHD, mais le traitement immunosuppresseur à l'évaluation endocrinienne est un marqueur d'une probable GVHD durable. II n'y avait pas de différence significative de survenue d'hypothyroïdie entre le groupe avec et le groupe sans traitement immunosuppresseur à l'évaluation endocrinienne. Au même titre que pour I'ICT, notre évaluation endocrinienne était plus précoce que celle de Savani et al. qui était réalisée à 84 mois. 
Enfin le conditionnement par busulfan n'est pas prédictif de la survenue d'une hypothyroïdie. Mais avec 13,3 \% d'hypothyroïdie sous traitement par busulfan comme sous ICT dans notre étude, cette fréquence est semblable à celle de 11,7 \% évoquée par AlFiar et al., qui constataient que la fréquence d'hypothyroïdie était similaire après conditionnement par busulfan-cyclophosphamide qu'après une ICT dans une population de greffés (auto et allogreffe). ${ }^{7}$

Concernant l'insuffisance thyréotrope, l'étude de Sanders et al. sur une large population pédiatrique allogreffée devenue adulte avait retrouvé 9,3\% d'insuffisance thyréotrope à 28 ans de la greffe. ${ }^{6}$ Les auteurs ne précisaient pas le type de traitement reçu par ces patients, mais il pouvait contenir une ICT de 10 à 15,75 Gy. L'étude de Kauppila et al., sur 20 patients adultes, avaient trouvé un cas d'insuffisance thyréotrope à 3 ans post-greffe. Aucune autre étude, adulte ou pédiatrique, ne signale d'insuffisance thyréotrope. ${ }^{36}$

Notre étude retrouve 2 patients présentant une insuffisance thyréotrope, dont une patiente qui n'avait pas reçu d'ICT. La présence d'une insuffisance thyréotrope chez cette dernière patiente semble surprenant, d'autant plus que son conditionnement était d'intensité réduite pour une LAM en première rémission. Cela ne permet pas d'incriminer de façon raisonnable la chimiothérapie.

Par ailleurs, il est connu que l'irradiation encéphalique à dose $<24$ Gy n'induit pas d'insuffisance thyréotrope. ${ }^{55}$

Nous avons peut-être diagnostiqué par excès deux insuffisances thyréotropes alors qu'il pourrait s'agir d'une diminution de la T4 libre secondaire à une pathologie aigüe ou chronique, comme il existe une diminution de la T3 (triiodothyronine) libre dans ces mêmes conditions (syndrome de basse T3). Néanmoins, les patients évalués en Endocrinologie sont en rémission complète et dans une situation médicale reconnue comme stable vis à vis de leur pathologie hématologique. Aucun n'est en insuffisance pondérale sauf une patiente.

Nous n'avons pas retrouvé d'hyperthyroïdie, ce qui n'est pas surprenant compte tenu des rares case-reports parus dans la littérature. Elle pourrait être provoquée par l'irradiation de la thyroïde notamment des enfants à plus de $35 \mathrm{~Gy},{ }^{10}$ ou par un possible transfert d'immunité du donneur devant la survenue concomitante d'une Maladie de Basedow chez un donneur et un receveur relatée en $1991 .^{56}$

\section{Axe corticotrope}

Nous avons retrouvé $19,5 \%$ de patients présentant une insuffisance corticotrope dans notre population étudiée, soit 8 patients. Cette fréquence est surévaluée car l'un des patients venait tout récemment de diminuer sa dose de glucocorticoïdes à une dose physiologique (prednisone 7,5 mg) et n'avait sûrement pas eu le temps de récupérer une fonction corticotrope normale.

Par rapport aux 4 études réalisées chez l'adulte retrouvant de 0 à $10 \%$ d'insuffisance corticotrope, $^{34-37}$ nos résultats montrent une fréquence bien plus grande. Néanmoins, seul Tauchmanovà et al. précisent le nombre de patients ayant bénéficié d'une corticothérapie (>65\%) avec 10\% d'insuffisance corticotrope sur un dépistage de moindre sensibilité (cortisol plasmatique à $8 \mathrm{~h}$ ). Notre différence d'incidence pourrait 
être due à une différence de population traitée par corticothérapie et aux modalités différentes de dépistage de l'insuffisance corticotrope.

7 patients parmi ceux en déficit avaient bénéficié d'une corticothérapie, dont 6 pour une durée supérieure à 3 mois. Aucun critère prédictif de survenue d'insuffisance corticotrope n'a été retrouvé dans notre étude, même si la corticothérapie $>1$ mois semble être un facteur de risque $(P=0,110)$ avec une fréquence de $29,2 \%$ vs $5,9 \%$.

Une patiente ayant une insuffisance corticotrope sans corticothérapie préalable avait bénéficié d'un conditionnement par ICT de 12 Gy et cyclophosphamide. II est difficile d'attribuer son déficit à I'ICT car les cellules corticotropes sont réputées être les plus résistantes de l'antéhypophyse. ${ }^{57}$ En effet, la littérature ne parle d'effet de l'irradiation sur l'axe corticotrope qu'à partir de $24 \mathrm{~Gy}^{58}$ et généralement plusieurs années après. ${ }^{59}$ Garg et al. retrouvent également une absence de sur-risque d'insuffisance corticotrope après corticothérapie dans son étude mixte (population enfants et adultes, auto et allogreffes). Ils évoquent alors une possible toxicité du busulfan-cyclophosphamide sur les cellules corticotropes. ${ }^{40}$ Dans notre étude, le conditionnement par busulfan ne semble pas être incriminé dans la survenue de cette insuffisance, et était même plutôt protecteur sans être significatif (fréquence de $15,4 \%$ vs $21,4 \%$ ). Ainsi, il n'est pas impossible que le cyclophosphamide soit responsable de l'insuffisance corticotrope de cette patiente.

Nous n'avons retrouvé, comme nous pouvions nous y attendre, aucune insuffisance surrénalienne périphérique. En effet, l'insuffisance surrénalienne primitive n'a été retrouvée que dans 2 case-reports isolés chez l'enfant. ${ }^{60,61}$

\section{Axe somatotrope}

Notre étude constate 14 déficits somatotropes sur 43 patients étudiés, soit 32,6\% de fréquence $(11,6 \%$ de déficits sévères et $20,9 \%$ de déficits partiels). 12 patients ont été diagnostiqués par le test d'hypoglycémie insulinique, un par un test à la GHRH-arginine et le dernier par un test au Glucagon-propranolol.

Le test d'hypoglycémie insulinique est le gold standard pour le diagnostic de l'insuffisance somatotrope, et, depuis les dernières recommandations de la GH Research Society, un seul test est suffisant pour porter le diagnostic. ${ }^{62}$ Néanmoins, ce test pourrait ne pas être le test le plus approprié en cas d'atteinte hypothalamique partielle post-radique. En effet, Darzy et al. évoquent de possibles atteintes hypothalamiques partielles bien compensées avec une sécrétion de GHRH au maximum de ses capacités. Le test d'hypoglycémie insulinique, qui stimule la sécrétion des neurones à $G H R H$, ne serait donc pas approprié alors qu'un test au GHRH-arginine permettrait de contrôler la fonction somatotrope hypophysaire. ${ }^{63}$

Les deux patients déficitaires en hormone de croissance et qui avaient bénéficié d'une ICT ont eu un test d'hypoglycémie insulinique. Leurs pics de $\mathrm{GH}$ étaient $<9 \mathrm{mUI} / \mathrm{l}$, témoin d'une insuffisance somatotrope sévère. D'après Darzy et al., ces deux patients pourraient avoir une insuffisance somatotrope bien compensée malgré un pic de GH insuffisant pendant le test d'hypoglycémie insulinique. La fréquence des déficits 
somatotropes de notre population pourrait donc possiblement être surestimée de deux patients et serait de $29,3 \%$ en excluant ces deux patients.

D'après la littérature adulte, la fréquence de l'insuffisance somatotrope postallogreffe est comprise entre 0 et $27 \%,{ }^{34-37}$ avec 4 méthodes d'exploration différentes (cf. Tableau 1). Notre fréquence, même corrigée par les patients conditionnés par ICT, est supérieure aux autres études. Elle est même en contradiction avec l'étude de Littley et $a l .$, la seule à utiliser le test d'hypoglycémie insulinique, qui ne retrouve pas d'insuffisance somatotrope (pic de $\mathrm{GH}>20 \mathrm{mUI} / \mathrm{l}$ ) chez les 18 patients testés. Notre fréquence de déficit en GH s'approche plus de celle des enfants allogreffés comprise entre 17 et $50 \%,{ }^{11,13-15}$ ou de celle de l'étude Garg et al. (36 \%) dans un population adulte mixte (auto et allogreffés) qui avait reçu un conditionnement par busulfan-cyclophosphamide sans ICT. ${ }^{40}$

Parmi les patients déficitaires, seuls 5 patients sur 14 avaient une IGF1 basse pour l'âge et le sexe. Par ailleurs, sur les 29 patients sans déficit somatotrope, 6 avaient une IGF1 basse pour l'âge et le sexe. Comme suggéré par Kauppila et al., ${ }^{36}$ I'IGF1 ne semble pas être un bon marqueur de dépistage de l'insuffisance somatotrope pour la population d'allogreffés adultes.

Notre analyse de corrélation n'a pas retrouvé de facteur prédictif de survenue d'insuffisance somatotrope.

L'ICT n'est pas un facteur de risque alors que l'axe somatotrope est réputé être le plus sensible aux irradiations. ${ }^{64}$ Chez l'adulte, à des doses moyennes d'irradiation encéphalique de $50 \mathrm{~Gy}$, l'insuffisance somatotrope survient entre 27,3 et $30 \% .{ }^{65,66}$ Dans notre étude, la fréquence d'insuffisance somatotrope s'approche de ces chiffres, mais après irradiation à doses bien plus faibles; il existe probablement d'autres facteurs que l'ICT influençant ce déficit chez l'allogreffé. Cette hypothèse peut être argumentée par les résultats des autres études chez l'adulte qui ne retrouvaient pas non plus I'ICT comme facteur de risque.

Dans notre étude, la présence d'une GVHD chronique sévère ou modérée a tendance à diminuer le risque du déficit en GH sans être significatif. Cela semble surprenant dans la mesure où les données de Sanders et al. montre que le déficit somatotrope des enfants est corrélé à l'atteinte systémique induite par la GVHD chronique. ${ }^{12}$

Enfin, le conditionnement par busulfan semble corrélé à une augmentation de la survenue du déficit somatotrope sans être significatif, avec une fréquence presque triple dans notre étude (41,4 \% vs $14,3 \%)$. Ce facteur de risque éventuel est contradictoire dans la littérature, ${ }^{17}$ mais expliquerait la fréquence de ce déficit chez l'adulte même en l'absence d'ICT comme dans l'étude de Garg et al. $^{40}$

Nous notons que, malgré les recommandations de la GH Research Society, ${ }^{62}$ aucun de nos patients déficitaires n'a bénéficié de traitement substitutif, notamment les insuffisants sévères. Si les études sont unanimement en faveur d'un traitement substitutif chez l'enfant avec de bons résultats sur la croissance, ${ }^{67}$ son usage chez l'adulte semble moins indispensable dans la mesure où il existerait une augmentation du risque de tumeur solide secondaire chez les enfants traités. ${ }^{68}$ Des études chez l'adulte doivent être réalisées pour rassurer le prescripteur et permettre une substitution chez ces patients afin d'éviter les conséquences de l'insuffisance somatotrope : ostéoporose, augmentation 
de la masse graisse, fatigabilité à l'effort, majoration du risque cardiovasculaire et altération de la qualité de vie. 62,69

\section{E. Axe gonadotrope}

\section{Chez la femme}

Dans notre étude, l'ensemble des patientes étaient en aménorrhée et avaient un profil hormonal en faveur d'une insuffisance ovarienne primitive ou de ménopause (FSH élevée et estradiol bas), à l'exception de deux patientes sous traitements estroprogestatifs mais dont le diagnostic d'insuffisance ovarienne primitive avait déjà été porté. Ce résultat est concordant avec la littérature qui retrouve, dans les populations allogreffées à l'âge adultes, de 90 à $100 \%$ d'atteinte gonadique chez les femmes. ${ }^{35-37,40}$

Aucune insuffisance gonadotrope n'a été reportée, ce qui est toujours le cas dansla littérature puisque l'atteinte des cellules gonadotropes est exceptionnelle après irradiation inférieure à $44 \mathrm{~Gy}$ ou suite à une chimiothérapie. ${ }^{64}$

Cette IOP systématique chez les femmes non-ménopausées au diagnostic de leur hémopathie n'est pas surprenante. En effet, toutes ces femmes ont bénéficié d'un conditionnement comprenant soit une ICT, soit du busulfan, à l'exception d'une patiente de 43 ans qui avait tout de même reçu un agent alkylant (cyclophosphamide). La littérature est unanime sur les effets cytotoxiques de la radiothérapie et de la chimiothérapie sur le follicule. La dose calculée d'irradiation nécessaire pour détruire $50 \%$ des ovocytes est de $4 \mathrm{~Gy} .{ }^{70}$ Le risque d'infertilité augmente selon la dose cumulée d'alkylants dont le busulfan, le melphalan et le cyclophosphamide. ${ }^{20}$

D'après l'étude prospective de Phelan et al. chez des femmes de 16 à 45 ans allogreffées, un conditionnement d'intensité réduite (cyclophosphamide-fludarabine ou melphalan-clofarabine) diminue l'incidence de l'IOP à $10 \%$ des femmes. ${ }^{71}$ Dans notre étude, $50 \%$ des femmes non-ménopausées au diagnostic d'hémopathie ont bénéficié d'un traitement d'intensité réduite, sans être protégées de l'IOP. Néanmoins, l'étude de Phelan et al. a été conduite sur une durée plus longue que la nôtre ( 2,5 ans postgreffe) et les auteurs précisent que 3 patientes ont récupéré un cycle menstruel au cours de l'étude. II n'est donc pas impossible que ce soit le cas chez nos patientes, notamment chez celles non traitées par ICT. Schimmer et al. ont étudié la récupération de la fonction gonadique chez 17 patientes allogreffées et montrent une récupération à 24 mois de moyenne dans $29 \%$ des cas dépendant notamment de I'ICT (20\% de récupération) et de I'âge ( $0 \%$ après 28 ans). ${ }^{72}$

L'AMH est un bon marqueur de la réserve ovarienne, également chez les femmes traitées pour une hémopathie. ${ }^{73}$ Nous n'avons pas dosé systématiquement l'AMH dans notre population car toutes les femmes étaient en aménorrhée, et donc fortement suspectes d'IOP.

Toutes les patientes ayant un âge inférieur à 50 ans et qui n'avaient pas de contreindication ont bénéficié d'une substitution estroprogestative. 


\section{Chez l'homme}

L'atteinte de la spermatogenèse a été évaluée dans notre étude par une mesure de la FSH plasmatique. La moitié des hommes de notre étude avait une FSH élevée. Certaines études parlent d'une atteinte sertolienne dès une $\mathrm{FSH}>10 \mathrm{UI} / \mathrm{I}^{74} \mathrm{En}$ prenant pour seuil cette valeur, 16 patients sur $18(88,9 \%)$ auraient une atteinte probable de la spermatogenèse. Ses deux fréquences correspondent aux données de la littérature retrouvant entre 47 et $100 \%$ d'élévation de la FSH post-greffe chez les adultes. ${ }^{34-37,40}$

Nous n'avons pas retrouvé de critère prédictif d'élévation de la FSH chez l'homme alors que l'irradiation corporelle totale est un très grand facteur de risque. En effet, l'atteinte sur la spermatogenèse commence dès une irradiation testiculaire de $0,5 \mathrm{~Gy}$ et est très souvent définitive après $6 \mathrm{~Gy}^{23} \mathrm{~A}$ ce sujet, le seul patient masculin irradié de notre étude n'avait pas d'élévation de sa FSH, ce qui semble surprenant. Une récupération de la spermatogenèse a été décrite après ICT pour allogreffe dans $17 \%$ des cas d'une population allogreffée dans l'enfance et devenue adulte, mais elle survenait toujours après 4 ans. $^{75}$

Les agents alkylants sont très toxiques sur l'épithélium germinale, avec un effet dosedépendant. ${ }^{76}$ Dans notre étude, le conditionnement par busulfan n'était pas un critère prédictif d'élévation de la $\mathrm{FSH}$, probablement car les autres patients avaient bénéficié d'un autre agent alkylant (cyclophosphamide ou melphalan). Un conditionnement myéloablatif, et donc avec des doses d'alkylant plus élevées, n'était pas non plus prédictif d'élévation de la FSH.

La GVHD et ses paramètres ne sont pas non plus corrélés à l'élévation de la FSH comme retrouvé dans une étude pédiatrique. ${ }^{22}$ Enfin, l'âge n'est pas corrélé à l'élévation de la $\mathrm{FSH}$, ce qui ne semble pas surprenant car les études pédiatriques retrouvaient une protection de l'élévation de la FSH chez les garçons prépubères traités par chimiothérapie. ${ }^{20,23}$ L'absence de puberté signifie une activité mitotique du tube germinale basse qui rend l'atteinte cellulaire par les agents alkylants plus difficile.

Même si la FSH n'est pas un marqueur suffisamment sensible de la spermatogenèse, ${ }^{77}$ il reste un marqueur très utilisé en pratique courante. L'étude de Garg et al. retrouvait $69 \%$ d'élévation de la FSH mais $100 \%$ d'azoospermie. $^{40}$ II faut donc, pour évaluer la fertilité des patients post-allogreffes, leur proposer un spermogramme. A ce titre, il convient de rappeler que la spermatogenèse peut être réversible plusieurs années après la greffe, comme le décrit Anserini et al., chez 50 à $90 \%$ des patients conditionné sans ICT. ${ }^{75}$

Un déficit en testostérone est retrouvé chez un seul patient de 54 ans soit 5,5\% de notre population masculine, et il s'agissait d'un hypogonadisme central (hypogonadotrophique). Ce patient n'a pas bénéficié d'ICT. Les quatre études réalisées chezl'adulte allogreffé ne retrouvait pas d'hypogonadisme hypogonadotrophique. ${ }^{34-37}$ Les études pédiatriques ne retrouvent pas non plus d'hypogonadisme hypogonadotrophique mais des hypogonadismes hypergonadotrophiques dans 9 à $23 \%$ des cas. ${ }^{13,15}$ Notre cas semble isolé d'autant plus que la chimiothérapie comme la radiothérapie <44 Gy n'est pas connue pour léser les cellules gonadotropes. ${ }^{64}$

Dans 40 à $45 \%$ des adultes post-greffes, il existe une atteinte leydigienne bien compensée, caractérisée par une augmentation de la LH sans baisse de la testostérone. ${ }^{35,36}$ Cette atteinte 
leydigienne bien compensée est présente dans notre étude chez $27,7 \%$ de nos patients. Aucun des 5 patients avec une élévation de la LH (compensée ou non) n'a été traité par ICT. L'atteinte testiculaire est possiblement secondaire à la chimiothérapie du conditionnement ou à la chimiothérapie antérieure à la greffe pour leur hémopathie.

D'un point de vue thérapeutique, nous avons proposé au patient présentant un hypogonadisme de contrôler sa testostéronémie et de réaliser une ostéodensitométrie avant d'envisager une substitution hormonale. Nous n'avons pas revu le patient par la suite.

\section{F. Conséquences Osseuses}

Notre étude retrouve $76,7 \%$ de diminution de la DMO dont 27,9 \% d'ostéoporose à 14,5 mois en moyenne post-greffe. Par rapport aux études les plus anciennes (DMO basse dans 39 à $53 \%$ ), nos fréquences sont plus importantes alors que l'âge moyen, le sex-ratio et la durée post-greffe sont similaires. Par contre, la proportion de femmes ayant une substitution estrogénique était plus grande dans l'étude de Kauppila et al. (98\%) et de Stern et al. (85\%) que dans notre étude ( $26 \%$ ). ${ }^{26,42}$ Dans notre étude, aucune patiente ménopausée avant l'hémopathie n'avait de traitement hormonal de la ménopause lors de l'ostéodensitométrie et elles avaient dans $90 \%$ des cas une baisse de leur DMO pouvant expliquer l'augmentation de la fréquence totale de notre étude. Enfin, les investigateurs de l'étude de Stern et al. supplémentaient également de façon systématique leurs patients en vitamine $D$.

Concernant les critères prédictifs de survenue d'une baisse de la DMO, le busulfan serait un facteur protecteur dans notre population, laissant penser que les autres chimiothérapies utilisées pour le conditionnement de l'allogreffe (melphalan et fludarabine notamment) sont plus cytotoxiques sur l'os. L'insuffisance somatotrope a tendance à être un facteur de risque de baisse de la DMO sans être significatif, ce qui ne nous surprend pas au vu de l'action positive de la GH et de l'IGF1 sur la minéralisation osseuse.

Ces deux critères prédictifs ne sont pas retrouvés pour l'ostéoporose qui, dans notre étude, est uniquement corrélée à une carence profonde en vitamine $D$ et à un âge supérieur à 50 ans. Cela renforce l'importance d'une substitution systématique en vitamine $D$ dans cette population très à risque. L'âge supérieur à 50 ans est un facteur de risque reconnu dans la population générale, notamment chez la femme suite à la ménopause. La forte proportion ayant une baisse de la DMO chez les femmes ménopausées avant l'hémopathie va également dans ce sens.

La corticothérapie ne ressort pas comme un critère prédictif de baisse de la DMO dans notre étude, probablement dû à un effectif trop faible.

Notre étude ne retrouve pas la prédominance d'atteinte fémorale décrite par la littérature, avec d'ailleurs plus d'atteinte vertébrale dans la baisse de la DMO comme dans l'ostéoporose. Cette différence entre atteinte trabéculaire (vertébrale) et corticale (fémorale) apparaît généralement après 5 ans post-greffe, signant une plus lente récupération de l'os cortical dans les suites de l'allogreffe. ${ }^{78}$

Nous restons critiques sur l'interprétation des résultats des ostéodensitométries. En effet, comme beaucoup d'études, et pour pouvoir être comparable, nous avons choisi 
d'utiliser le T-score pour estimer la DMO. Néanmoins, le T-score compare la DMO du sujet au pic maximal d'une population de référence (autour de 20-30 ans) et est surtout utilisé pour une population de femmes ménopausées. Dans notre population âgée en moyenne de 47,2 ans à l'évaluation, nous aurions pu utiliser le Z-score qui se rapporte à une population de référence de même âge.

$75 \%$ de nos patients avaient une carence en vitamine D, comme dans l'étude de Myers et al. où $73 \%$ des patients (enfants et jeunes adultes) étaient carencés. ${ }^{79}$ La vitamine $D$ aurait des effets immuno-modulateurs, et une étude rétrospective de 53 patients allogreffés a montré une corrélation significative entre le déficit en vitamine $D$ pré-greffe et la survenue de GVHD chronique. ${ }^{80}$

\section{G. Conséquences Métaboliques}

L'IMC moyen des patients était de $24,4 \mathrm{~kg} / \mathrm{m}^{2}$ avec une proportion de patients en surpoids de $15,6 \%$ et obèses de $20 \%$ pour un âge moyen de 47,2 ans. L'étude française Constances retrouve, pour un âge de 40 à 49 ans, une prévalence d'obèses de 13,8\% des femmes et de 16,8\% des hommes. ${ }^{81}$ L'étude française ObEpi 2012 constate, entre 45 et 54 ans, un IMC moyen de $25,8 \mathrm{~kg} / \mathrm{m}^{2}$ et une prévalence du surpoids de $34,8 \%$ et de l'obésité de $16 \%{ }^{82}$ Notre population présente donc une proportion d'obèses plus importante et une proportion moindre de patients en surpoids. Néanmoins, nos caractéristiques correspondent aux moyennes d'une population d'âges très différents (de 18 à 64 ans).

La fréquence des dyslipidémies est forte, avec un taux de 45,5\% des patients de notre étude. Un seul patient avait une hypercholestérolémie en se basant sur un taux $>1,90 \mathrm{~g} / \mathrm{l}$, mais 3 patients étaient traités par statine. La fréquence d'hypertriglycéridémie était importante, atteignant presqu'un tiers des patients $(31,8 \%)$ avec une proportion similaire de diminution du taux d'HDL (29,5\%). L'étude épidémiologique EURIKA, portant sur 7641 patients européens de plus de 50 ans (âge moyen: 63,2 ans), retrouvait une proportion de $20 \%$ de dyslipidémie (soit hypertriglycéridémie, soit baisse du HDL). ${ }^{83}$ Notre population a donc une proportion de dyslipidémie 2 fois plus importante qu'une population de référence bien plus âgée. Puisque la fréquence de l'insulino-résistance de nos patients n'est pas majorée ( $c f$. infra), ces dyslipidémies pourraient être attribuées à une toxicité directe des traitements anti-cancéreux, d'autant plus que les IMC des patients atteints sont souvent normaux.

Deux patients avaient une hyperglycémie modérée à jeun $\geq 1,1 \mathrm{~g} / \mathrm{l}(4,4 \%)$ et deux patients ont présenté un diabète cortico-induit traité par règles hygiéno-diététiques à l'évaluation. Cette fréquence d'hyperglycémie modérée à jeun n'est pas différente de celle de l'étude épidémiologique française EPIMIL, réalisée chez 2045 hommes militaires, qui était de $5 \%{ }^{84}$ Concernant I'insulino-résistance estimée par I'HOMA2-IR, 8 patients $(17,8 \%)$ avaient un index d'insulino-résistance (HOMA2-IR) élevé. L'HOMA2-IR reste une méthode d'estimation qui sous-estime l'insulino-résistance en comparaison au gold standard qu'est le clamp euglycémique hyperinsulinique. ${ }^{85}$ L'insulino-résistance est définie par l'OMS comme les $25 \%$ les plus insulinorésistants après un clamp euglycémique hyperinsulinique. ${ }^{86}$ Notre population ne présente pas de majoration de l'insulino-résistance. Néanmoins, des 
études réalisés chez des adultes allogreffés dans l'enfance montrent une fréquence du diabète et de l'intolérance au glucose à 10 ans pouvant atteindre $69 \%$ des patients. ${ }^{87}$ Une évaluation des patients allogreffés à l'âge adulte à 10 ans post-greffe nous permettrait de confirmer que l'insulino-résistance est également une complication à long terme dans cette population.

Un conditionnement par busulfan ou une prophylaxie par mycophénolate mofétil sont associés à une augmentation de l'insulino-résistance. Ces résultats sont intéressants car les effets sur le métabolisme glucidique du mycophénolate mofétil ou du busulfan ont été peu étudiés. Le mycophénolate mofétil n'aurait pas d'effet in vitro sur la sécrétion descellules ß-pancréatiques humaines. ${ }^{31}$ Quant au busulfan, à notre connaissance, aucune étude in vitro n'a été réalisée et l'étude clinique de Oudin et al. ne montrait pas d'augmentation du syndrome métabolique chez les enfants allogreffés avec du busulfan comme conditionnement. ${ }^{88}$

\section{H. Critiques positives et négatives}

Notre étude rétrospective a étudié les conséquences endocriniennes chez 45 patients allogreffés après l'âge de 16 ans. Elle complète les quatre autres études réalisées dans cette population qui avaient également mené une exploration exhaustive des conséquences hormonales tandis que la population pédiatrique bénéficie d'une littérature plus fournie.

Notre effectif est légèrement plus important que l'étude la plus récente de Tauchmanovà et al. qui comportait 40 patients. ${ }^{37}$ Les trois autres études (Benker et al., Littley et al., Kauppila et al.) comportaient respectivement 23,21 et 20 patients. ${ }^{34-36}$

En termes de durée post-greffe à l'évaluation endocrinienne, notre travail est moins hétérogène que les autres études et plus précoce, avec une moyenne de 14,5 mois et seulement un patient évalué à plus de 24 mois. Nos résultats correspondent donc raisonnablement aux conséquences endocriniennes survenant dans les deux premières années post-greffe.

Notre étude, bien que rétrospective, est basée sur un recueil de données exhaustif, incluant une évaluation endocrinienne standardisée des patients. Surtout, nous avons réalisé une étude hormonale basée sur des dosages statiques et des tests dynamiques de stimulation, considérés comme les "gold standard" pour mieux diagnostiquer d'éventuels déficits. L'ensemble de ces tests n'était pas réalisé dans les études précédemment publiées.

L'autre originalité de notre travail réside dans l'étude complémentaire desconséquences osseuses et métaboliques. Les conséquences métaboliques n'ont, à notre connaissance, jamais été étudiées dans la population allogreffée à l'âge adulte.

Néanmoins, il s'agit d'une étude rétrospective et monocentrique avec un faible effectif. Ce faible effectif s'explique d'une part par la faible prévalence de l'allogreffe dans la population générale, et d'autre part, par sa mortalité, directe ou liée à l'hémopathie, qui reste encore élevée.

Sur les 148 patients explorables en Endocrinologie (Figure 1), seulement $42 \%$ ont bénéficié d'une évaluation endocrinienne et $30 \%$ ont été inclus. II existe donc un fort biais de sélection. Cette faible proportion de patients explorés est expliquée par une exploration non systématisée et des raisons médicales prioritaires. 
Une limite à l'interprétation de nos résultats est l'absence de prise en compte des thérapeutiques antérieures à la greffe, souvent des chimiothérapies, qui participent également à la survenue des conséquences endocriniennes. Nous ne connaissons pas non plus les statuts hormonaux, métaboliques et osseux des patients avant l'allogreffe. Il existe d'autre biais d'information comme la variabilité des pathologies hématologiques et des conditionnements d'allogreffe différents.

Pour les analyses statistiques, le faible effectif est responsable d'un manque de puissance pour obtenir une significativité, comme le montre l'absence de significativité de la corrélation entre insuffisance corticotrope et traitement par corticoïdes de synthèse. De même, il existe des facteurs confondants dans nos analyses, notamment ceux concernant l'ostéoporose (âge et vitamine D) et l'insulino-résistance (IMC). Mais notre faible effectif ne nous permet pas de réaliser une analyse multivariée.

Certaines données cliniques n'ont pas été recueillies dans cette étude, comme le tour de taille et le statut tensionnel des patients, afin d'estimer la fréquence du syndrome métabolique dans notre population. Des données biologiques d'intérêt concernant les dysthyroïdies auraient pu étayer notre étude comme le dosage de la T3 libre, pour ne pas méconnaitre d'éventuel syndrome de basse T3, et le dosage des anticorps anti-TPO pour les thyroïdites auto-immunes. L'albumine aurait pu aussi nous donner des informations sur l'état nutritionnel des patients, données pertinentes pour ne pas surestimer notamment les insuffisances somatotropes secondaires à la dénutrition.

Enfin, les mécanismes permettant d'expliquer certaines atteintes sont connus mais d'autres, en particulier les atteintes hypophysaires chez des patients non irradiés, restent inconnus et n'ont pas été explorés dans cette étude.

Ce travail a néanmoins permis de confirmer les quelques données de la littérature sur la prévalence des conséquences endocriniennes à court terme des allogreffes en les étayant par les études dynamiques sur tous les axes endocriniens. II est probable, au vue de la littérature chez l'enfant, qu'un suivi au plus cours est nécessaire ainsi qu'une exploration plus systématique des patients. 


\section{CONCLUSION}

Les complications endocriniennes de l'allogreffe chez l'enfant ont été fortement étudiées ces vingt dernières années. Notre étude est, à notre connaissance, l'une des rares à explorer l'ensemble des conséquences endocriniennes de l'allogreffe réalisée à un âge adulte pour une hémopathie maligne. Elle est également la seule à explorer leur statut métabolique.

Nous avons réalisé une évaluation hormonale, osseuse et métabolique chez 45 patients allogreffés entre 2006 et 2016 au CHRU de Brest à 14,5 mois post-greffe.

Nos résultats montrent une forte proportion d'atteinte hormonale. En premier lieu, l'atteinte gonadique est systématique chez les femmes antérieurement réglées, et est présente chez la moitié des hommes (atteinte de la spermatogenèse).

L'atteinte antéhypophysaire touche presque la moitié des patients. Parmi les atteintes antéhypophysaires, nous avons retrouvé des déficits de l'axe gonadotrope, pourtant réputé être résistant au conditionnement de l'allogreffe, et de l'axe thyréotrope, rarement atteint. Presque un tiers des patients présentent une insuffisance somatotrope et un cinquième une insuffisance corticotrope. De plus, une patiente en déficit corticotrope n'avait pas été traitée par corticoïdes de synthèse et nous attribuons son déficit à son conditionnement par cyclophosphamide.

Enfin, plus d'un patient sur dix présentent une dysthyroïdie soit une hypothyroïdie périphérique, soit une hypothyroïdie infra-clinique, soit une insuffisance thyréotrope, en proportion égale. Un âge inférieur à 30 ans à l'allogreffe était prédictif d'une survenue d'hypothyroïdie.

Concernant leur densité minérale osseuse, la moitié des patients est atteinte d'une ostéopénie et plus d'un quart d'une ostéoporose. Cette fréquence est plus importante que celle décrite par le reste de la littérature, possiblement à cause de facteurs confondants (forte proportion de femmes ménopausées et de carence en vitamine $D$ ). Un conditionnement par busulfan était prédictif d'une absence de baisse de la DMO.

D’un point de vue métabolique, l'obésité et la dyslipidémie sont plus fréquentes que dans la population générale, atteignant respectivement un patient sur cinq et presque un patient sur deux. Puisque notre population n'est pas plus insulino-résistante que la population générale (étude de I'HOMA-IR), cette dyslipidémie est possiblement attribuable à une toxicité directe des traitements anti-cancéreux ou aux immunosuppresseurs.

Certaines conséquences endocriniennes peuvent être transitoires (gonades, thyroïde, DMO) et les conséquences métaboliques semblent être plus franches à 10 ans chez les adultes allogreffés dans l'enfance. Une étude prospective et longitudinale permettrait d'avoir une meilleure connaissance de l'évolution et de l'apparition tardive des troubles endocriniens chez les patients allogreffés à l'âge adulte.

En conclusion, les conséquences endocriniennes chez l'adulte allogreffé sont nombreuses et fréquentes, et justifient un dépistage régulier afin de leur proposer une prise charge susceptible d'améliorer leur qualité de vie. 


\section{ANNEXES}

\begin{tabular}{|c|c|c|c|}
\hline & & $\begin{array}{c}\text { Fréquence d'Hypothyroïdie } \\
\text { périphérique } \\
\text { no./total (\%) }\end{array}$ & Valeur de $\mathbf{P}$ \\
\hline \multirow[t]{2}{*}{ Sexe } & Femme & $3 / 26(11,5 \%)$ & \multirow{2}{*}{0,634} \\
\hline & Homme & $1 / 18(5,6 \%)$ & \\
\hline \multirow[t]{2}{*}{ Age à la greffe } & $<30$ ans & $2 / 7(28,6 \%)$ & \multirow{2}{*}{0,113} \\
\hline & $>30$ ans & $2 / 37(5,4 \%)$ & \\
\hline \multirow[t]{2}{*}{ Irradiation Corporelle Totale } & Oui & $0 / 8(0,0 \%)$ & \multirow{2}{*}{1,000} \\
\hline & Non & $4 / 36(11,1 \%)$ & \\
\hline \multirow[t]{2}{*}{ Conditionnement par Busulfan } & Oui & $3 / 30(10,0 \%)$ & \multirow{2}{*}{1,000} \\
\hline & Non & $1 / 14(7,1 \%)$ & \\
\hline \multirow[t]{2}{*}{ Prophylaxie GVHD par Methotrexate } & Oui & $1 / 16(6,3 \%)$ & \multirow{2}{*}{1,000} \\
\hline & Non & $3 / 28(10,7 \%)$ & \\
\hline \multirow[t]{2}{*}{ Prophylaxie GVHD par Mycophénolate mofétil } & Oui & $3 / 21(14,3 \%)$ & \multirow{2}{*}{0,335} \\
\hline & Non & $1 / 23(4,3 \%)$ & \\
\hline \multirow[t]{2}{*}{ Traitement par immunosuppresseur lors de l'évaluation } & Oui & $1 / 15(6,7 \%)$ & \multirow{2}{*}{1,000} \\
\hline & Non & $3 / 30(10,0 \%)$ & \\
\hline \multirow[t]{2}{*}{ GVHD aigüe } & Oui & $1 / 21(4,8 \%)$ & \multirow{2}{*}{0,609} \\
\hline & Non & $3 / 23(13,0 \%)$ & \\
\hline \multirow[t]{2}{*}{ GVHD chronique } & Oui & $2 / 19(10,5 \%)$ & \multirow{2}{*}{1,000} \\
\hline & Non & $2 / 25(8,0 \%)$ & \\
\hline \multirow[t]{2}{*}{ GVHD chronique et/ou aigüe } & Oui & $3 / 32(9,4 \%)$ & \multirow{2}{*}{1,000} \\
\hline & Non & $1 / 12(8,3 \%)$ & \\
\hline \multirow[t]{2}{*}{ GVHD dépendante à la corticothérapie } & Oui & $0 / 7(0,0 \%)$ & \multirow{2}{*}{1,000} \\
\hline & Non & $4 / 38(10,5 \%)$ & \\
\hline \multirow[t]{2}{*}{ GVHD modérée/sévère } & Oui & $0 / 12(0,0 \%)$ & \multirow{2}{*}{0,561} \\
\hline & Non & $4 / 32(12,5 \%)$ & \\
\hline
\end{tabular}

Nombre total de patients avec données, $n=44$ car une patiente exclue (thyroïdectomie) Abbréviations : GVHD, Graft vs Host Disease.

Annexe 1. Critères prédictifs de survenue d'hypothyroïdie périphérique (vraie et infraclinique). 


\begin{tabular}{|c|c|c|c|}
\hline & & $\begin{array}{c}\text { Fréquence d'Insuffisance } \\
\text { somatotrope sévère } \\
\text { no./total (\%) }\end{array}$ & Valeur de $\mathrm{P}$ \\
\hline \multirow[t]{2}{*}{ Sexe } & Femme & $3 / 25(12,0 \%)$ & \multirow{2}{*}{1,000} \\
\hline & Homme & $2 / 18(11,1 \%)$ & \\
\hline \multirow[t]{2}{*}{ Age à la greffe } & $<30$ ans & $1 / 7(14,3 \%)$ & \multirow{2}{*}{1,000} \\
\hline & $>30$ ans & $4 / 36(11,1 \%)$ & \\
\hline \multirow[t]{2}{*}{ IMC } & $<20 \mathrm{~kg} / \mathrm{m} 2$ & $1 / 10(10,0 \%)$ & \multirow{2}{*}{1,000} \\
\hline & $>20 \mathrm{~kg} / \mathrm{m} 2$ & $4 / 33(12,1 \%)$ & \\
\hline \multirow[t]{2}{*}{ Irradiation Corporelle Totale } & Oui & $2 / 8(25,0 \%)$ & \multirow{2}{*}{0,228} \\
\hline & Non & $3 / 35(8,6 \%)$ & \\
\hline \multirow[t]{2}{*}{ Conditionnement par Busulfan } & Oui & $3 / 29(10,3 \%)$ & \multirow{2}{*}{1,000} \\
\hline & Non & $2 / 14(14,3 \%)$ & \\
\hline \multirow[t]{2}{*}{ Prophylaxie GVHD par Methotrexate } & Oui & $3 / 16(18,8 \%)$ & \multirow{2}{*}{0,344} \\
\hline & Non & $2 / 27(7,4 \%)$ & \\
\hline \multirow[t]{2}{*}{ Prophylaxie GVHD par Mycophénolate mofétil } & Oui & $1 / 20(5,0 \%)$ & \multirow{2}{*}{0,351} \\
\hline & Non & $4 / 23(17,4 \%)$ & \\
\hline \multirow[t]{2}{*}{ Traitement par immunosuppresseur lors de l'évaluation } & Oui & $0 / 15(0,0 \%)$ & \multirow{2}{*}{0,145} \\
\hline & Non & $5 / 28(17,9 \%)$ & \\
\hline \multirow[t]{2}{*}{ GVHD aigüe } & Oui & $4 / 21(19,0 \%)$ & \multirow{2}{*}{0,185} \\
\hline & Non & $1 / 22(4,5 \%)$ & \\
\hline \multirow[t]{2}{*}{ GVHD chronique } & Oui & $1 / 17(5,9 \%)$ & \multirow{2}{*}{0,633} \\
\hline & Non & $4 / 26(15,4 \%)$ & \\
\hline \multirow[t]{2}{*}{ GVHD chronique et/ou aigüe } & Oui & 4/31 (12,9\%) & \multirow{2}{*}{1,000} \\
\hline & Non & $1 / 12(8,3 \%)$ & \\
\hline \multirow[t]{2}{*}{ GVHD dépendante à la corticothérapie } & Oui & $1 / 6(16,7 \%)$ & \multirow{2}{*}{0,547} \\
\hline & Non & $4 / 37(10,8 \%)$ & \\
\hline \multirow[t]{2}{*}{ GVHD modérée/sévère } & Oui & $1 / 11(9,1 \%)$ & \multirow{2}{*}{1,000} \\
\hline & Non & $4 / 32(12,5 \%)$ & \\
\hline
\end{tabular}

Nombre total de patients avec données, $n=43$, car 2 patients aux résultats non-interprétables Abbréviations : IMC, Indice de Masse Corporelle; GVHD, Graft vs Host Disease.

Annexe 2. Critères prédictifs de survenue d'insuffisance somatotrope sévère. 


\section{RÉFÉRENCES BIBLIOGRAPHIQUES}

1. Hilgendorf, I. et al. Long-term follow-up after allogeneic stem cell transplantation. Dtsch. Ärztebl. Int. 112, 51-58 (2015).

2. Gratwohl, A. et al. One million haemopoietic stem-cell transplants: a retrospective observational study. Lancet Haematol. 2, e91-100 (2015).

3. Berbis, J. et al. A French cohort of childhood leukemia survivors: impact of hematopoietic stem cell transplantation on health status and quality of life. Biol. Blood Marrow Transplant. J. Am. Soc. Blood Marrow Transplant. 19, 1065-1072 (2013).

4. Khera, N. et al. Nonmalignant late effects and compromised functional status in survivors of hematopoietic cell transplantation. J. Clin. Oncol. Off. J. Am. Soc. Clin. Oncol. 30, 71-77 (2012).

5. Nandagopal, R., Laverdière, C., Mulrooney, D., Hudson, M. M. \& Meacham, L. Endocrine Late Effects of Childhood Cancer Therapy: A Report from the Children's Oncology Group. Horm. Res. Paediatr. 69, 65-74 (2008).

6. Sanders, J. E. et al. Thyroid function following hematopoietic cell transplantation in children: 30 years' experience. Blood 113, 306-308 (2009).

7. Al-Fiar, F. et al. Abnormal thyroid stimulating hormone (TSH) levels in adults following allogeneic bone marrow transplants. Bone Marrow Transplant. 19, 1019-1022 (1997).

8. Berger, C. et al. Late thyroid toxicity in $\mathbf{1 5 3}$ long-term survivors of allogeneic bone marrow transplantation for acute lymphoblastic leukaemia. Bone Marrow Transplant. 35, 991-995 (2005).

9. Ishiguro, H. et al. Long-Term Follow-Up of Thyroid Function in Patients Who Received Bone Marrow Transplantation during Childhood and Adolescence. J. Clin. Endocrinol. Metab. 89, 5981-5986 (2004).

10. Sklar, C. et al. Abnormalities of the Thyroid in Survivors of Hodgkin's Disease: Data from the Childhood Cancer Survivor Study. J. Clin. Endocrinol. Metab. 85, 3227-3232 (2000).

11. Ogilvy-Stuart, A. L. et al. Endocrine deficit after fractionated total body irradiation. Arch. Dis. Child. 67, 1107-1110 (1992).

12. Sanders, J. E. et al. Growth and development following marrow transplantation for leukemia. Blood 68, 1129-1135 (1986).

13. Bajwa, R. et al. Metabolic syndrome and endocrine dysfunctions after HSCT in children. Pediatr. Transplant. 16, 872878 (2012).

14. Chung, S. J. et al. Growth after hematopoietic stem cell transplantation in children with acute myeloid leukemia. J. Korean Med. Sci. 28, 106-113 (2013).

15. Felicetti, F. et al. Endocrine late effects after total body irradiation in patients who received hematopoietic cell transplantation during childhood: a retrospective study from a single institution. J. Cancer Res. Clin. Oncol. 137, 1343 (2011).

16. Cohen, A. et al. Final Height of Patients Who Underwent Bone Marrow Transplantation for Hematological Disorders During Childhood: A Study by the Working Party for Late Effects-EBMT. Blood 93, 4109-4115 (1999).

17. Orio, F. et al. Endocrinopathies after Allogeneic and Autologous Transplantation of Hematopoietic Stem Cells. Sci. World J. 2014, 1-13 (2014).

18. Liesner, R. J., Leiper, A. D., Hann, I. M. \& Chessells, J. M. Late effects of intensive treatment for acute myeloid leukemia and myelodysplasia in childhood. J. Clin. Oncol. Off. J. Am. Soc. Clin. Oncol. 12, 916-924 (1994).

19. Dvorak, C. C. et al. NCl, NHLBI/PBMTC First International Conference on Late Effects after Pediatric Hematopoietic Cell Transplantation: Endocrine Challenges-Thyroid Dysfunction, Growth Impairment, Bone Health, \& Reproductive Risks. Biol. Blood Marrow Transplant. 17, 1725-1738 (2011).

20. Green, D. M. et al. Cumulative alkylating agent exposure and semen parameters in adult survivors of childhood cancer: a report from the St Jude Lifetime Cohort Study. Lancet Oncol. 15, 1215-1223 (2014).

21. Warne, G. L., Fairley, K. F., Hobbs, J. B. \& Martin, F. I. Cyclophosphamide-induced ovarian failure. N. Engl. J. Med. 289, 1159-1162 (1973).

22. Rovo, A. et al. Ongoing graft-versus-host disease is a risk factor for azoospermia after allogeneic hematopoietic stem cell transplantation: a survey of the Late Effects Working Party of the European Group for Blood and Marrow Transplantation. Haematologica 98, 339-345 (2013).

23. Kenney, L. B. et al. Male Reproductive Health After Childhood, Adolescent, and Young Adult Cancers: A Report From the Children's Oncology Group. J. Clin. Oncol. 30, 3408-3416 (2012).

24. Yao, S. et al. High prevalence of early-onset osteopenia/osteoporosis after allogeneic stem cell transplantation and improvement after bisphosphonate therapy. Bone Marrow Transplant. 41, 393-398 (2007).

25. Carpenter, P. A. et al. National Institutes of Health Consensus Development Project on Criteria for Clinical Trials in Chronic Graft-versus-Host Disease: V. The 2014 Ancillary Therapy and Supportive Care Working Group Report. Biol. Blood Marrow Transplant. J. Am. Soc. Blood Marrow Transplant. 21, 1167-1187 (2015).

26. Stern, J. M. et al. Bone density loss after allogeneic hematopoietic stem cell transplantation: A prospective study. Biol. Blood Marrow Transplant. 7, 257-264 (2001).

27. Gnudi, S., Butturini, L., Ripamonti, C., Avella, M. \& Bacci, G. The effects of methotrexate (MTX) on bone. A densitometric study conducted on 59 patients with MTX administered at different doses. Ital. J. Orthop. Traumatol. 14, 227-231 (1988). 
28. McClune, B., Majhail, N. S. \& Flowers, M. E. D. Bone loss and avascular necrosis of bone after hematopoietic cell transplantation. Semin. Hematol. 49, 59-65 (2012).

29. Cornillon, J. et al. Suivi et prise en charge des troubles endocriniens en post-greffe de cellules souches hématopoïétiques : dyslipidémie et thyropathie. Pathol. Biol. 61, 168-170 (2013).

30. Beauloye, V., Steffens, M., Zech, F., Vermylen, C. \& Maiter, D. Characterization of insulin resistance in young adult survivors of childhood acute lymphoblastic leukaemia and non-Hodgkin lymphoma. Clin. Endocrinol. (Oxf.) 78, 790798 (2013).

31. Vantyghem, M.-C., Marcelli-Tourvielle, S., Pattou, F. \& Noël, C. Effects of non-steroid immunosuppressive drugs on insulin secretion in transplantation. Ann. Endocrinol. 68, 21-27 (2007).

32. Majhail, N. S., Lazarus, H. M. \& Burns, L. J. Iron overload in hematopoietic cell transplantation. Bone Marrow Transplant. 41, 997-1003 (2008).

33. Lipshultz, S. E. et al. Long-term Cardiovascular Toxicity in Children, Adolescents, and Young Adults Who Receive Cancer Therapy: Pathophysiology, Course, Monitoring, Management, Prevention, and Research Directions: A Scientific Statement From the American Heart Association. Circulation 128, 1927-1995 (2013).

34. Benker, G. et al. Allogenic bone marrow transplantation in adults: endocrine sequelae after 1-6 years. Acta Endocrinol. (Copenh.) 120, 37-42 (1989).

35. Littley, M. D., Shalet, S. M., Morgenstern, G. R. \& Deakin, D. P. Endocrine and reproductive dysfunction following fractionated total body irradiation in adults. Q. J. Med. 78, 265-274 (1991).

36. Kauppila, M., Koskinen, P., Irjala, K., Remes, K. \& Viikari, J. Long-term effects of allogeneic bone marrow transplantation (BMT) on pituitary, gonad, thyroid and adrenal function in adults. Bone Marrow Transplant. 22, 331337(1998).

37. Tauchmanovà, L. et al. High prevalence of endocrine dysfunction in long-term survivors after allogeneic bone marrow transplantation for hematologic diseases: Endocrine Dysfunction after Allo-BMT. Cancer 95, 1076-1084 (2002).

38. Al-Hazzouri, A., Cao, Q., Burns, L. J., Weisdorf, D. J. \& Majhail, N. S. Similar risks for hypothyroidism after allogeneic hematopoietic cell transplantation using TBI-based myeloablative and reduced-intensity conditioning regimens. Bone Marrow Transplant. 43, 949-951 (2008).

39. Thomas, O. et al. Long-term complications of total body irradiation in adults. Int. J. Radiat. Oncol. 49, 125-131 (2001).

40. Garg, M. et al. Endocrine complications after busulphan and cyclophosphamide based hematopoietic stem cell transplant: A single tertiary care centre experience. Indian J. Endocrinol. Metab. 17, 855 (2013).

41. Schulte, C. M. S. \& Beelen, D. W. Bone loss following hematopoietic stem cell transplantation: a long-term follow-up. Blood 103, 3635-3643 (2004).

42. Kauppila, M. et al. Bone mineral density after allogeneic bone marrow transplantation. Bone Marrow Transplant. 24, (1999).

43. Schimmer, A. D. et al. Decreased bone mineral density is common after autologous blood or marrow transplantation. Bone Marrow Transplant. 28, 387-391 (2001).

44. Filipovich, A. H. et al. National Institutes of Health Consensus Development Project on Criteria for Clinical Trials in Chronic Graft-versus-Host Disease: I. Diagnosis and Staging Working Group Report. Biol. Blood Marrow Transplant. 11, 945-956 (2005).

45. Chaker, L., Bianco, A. C., Jonklaas, J. \& Peeters, R. P. Hypothyroidism. Lancet 390,1550-1562 (2017).

46. Surks, M. I. \& Ocampo, E. Subclinical thyroid disease. Am. J. Med. 100, 217-223 (1996).

47. Persani, L. Central Hypothyroidism: Pathogenic, Diagnostic, and Therapeutic Challenges. J. Clin. Endocrinol. Metab. 97, 3068-3078 (2012).

48. Fleseriu, M. et al. Hormonal Replacement in Hypopituitarism in Adults: An Endocrine Society Clinical Practice Guideline. J. Clin. Endocrinol. Metab. 101, 3888-3921 (2016).

49. Ho, K. K. Y. \& Participants, on behalf of the 2007 G. D. C. W. Consensus guidelines for the diagnosis and treatment of adults with GH deficiency II: a statement of the GH Research Society in association with the European Society for Pediatric Endocrinology, Lawson Wilkins Society, European Society of Endocrinology, Japan Endocrine Society, and Endocrine Society of Australia. Eur. J. Endocrinol. 157, 695-700 (2007).

50. Kanis, J. A., Melton, L. J., Christiansen, C., Johnston, C. C. \& Khaltaev, N. The diagnosis of osteoporosis. J. Bone Miner. Res. Off. J. Am. Soc. Bone Miner. Res. 9, 1137-1141 (1994).

51. Levy, J. C., Matthews, D. R. \& Hermans, M. P. Correct homeostasis model assessment (HOMA) evaluation uses the computer program. Diabetes Care 21, 2191-2192 (1998).

52. Radikova, Z. et al. Insulin Sensitivity Indices: a Proposal of Cut-Off Points for Simple Identification of Insulin-Resistant Subjects. Exp. Clin. Endocrinol. Diabetes 114, 249-256 (2006).

53. Carlson, K., Lönnerholm, G., Smedmyr, B., Oberg, G. \& Simonsson, B. Thyroid function after autologous bone marrow transplantation. Bone Marrow Transplant. 10, 123-127 (1992).

54. Hamnvik, O.-P. R., Larsen, P. R. \& Marqusee, E. Thyroid Dysfunction from Antineoplastic Agents. JNCI J. Natl. Cancer Inst. 103, 1572-1587 (2011).

55. Sathyapalan, T. \& Dixit, S. Radiotherapy-induced hypopituitarism: a review. Expert Rev. Anticancer Ther. 12, 669-683 (2012).

56. Meistrich, M. L. Effects of chemotherapy and radiotherapy on spermatogenesis in humans. Fertil. Steril. 100, 11801186 (2013).

57. Cornillon, J. et al. Suivi et prise en charge des troubles endocriniens en post-greffe de cellules souches 
hématopoiétiques : insuffisance corticotrope et ostéoporose. Pathol. Biol. 61, 171-173 (2013).

58. Le Meignen, M. et al. Bone mineral density in adult survivors of childhood acute leukemia: impact of hematopoietic stem cell transplantation and other treatment modalities. Blood 118, 1481-1489 (2011).

59. Weilbaecher, K. N. Mechanisms of osteoporosis after hematopoietic cell transplantation. Biol. Blood Marrow Transplant. 6, 165-174 (2000).

60. Ooms, M. E., Lips, P., Van Lingen, A. \& Valkenburg, H. A. Determinants of bone mineral density and risk factors for osteoporosis in healthy elderly women. J. Bone Miner. Res. Off. J. Am. Soc. Bone Miner. Res. 8, 669-675 (1993).

61. Rooney, D. P. \& Ryan, M. F. Diabetes with partial lipodystrophy following sclerodermatous chronic graft vs. host disease. Diabet. Med. J. Br. Diabet. Assoc. 23, 436-440 (2006).

62. American Heart Association et al. Diagnosis and management of the metabolic syndrome. An American Heart Association/National Heart, Lung, and Blood Institute Scientific Statement. Executive summary. Cardiol. Rev. 13, 322327 (2005).

63. Savastano, S., Di Somma, C., Barrea, L. \& Colao, A. The complex relationship between obesity and the somatropic axis: the long and winding road. Growth Horm. IGF Res. Off. J. Growth Horm. Res. Soc. Int. IGF Res. Soc. 24, 221-226 (2014).

64. Pucci, G. et al. Sex- and gender-related prevalence, cardiovascular risk and therapeutic approach in metabolic syndrome: A review of the literature. Pharmacol. Res. 120, 34-42 (2017).

65. Roos, A., Bakker, S. J. L., Links, T. P., Gans, R. O. B. \& Wolffenbuttel, B. H. R. Thyroid function is associated with components of the metabolic syndrome in euthyroid subjects. J. Clin. Endocrinol. Metab. 92, 491-496 (2007).

66. Chueh, H. W. \& Yoo, J. H. Metabolic syndrome induced by anticancer treatment in childhood cancer survivors. Ann. Pediatr. Endocrinol. Metab. 22, 82-89 (2017).

67. Bidlingmaier, M. et al. Reference Intervals for Insulin-like Growth Factor-1 (IGF-I) From Birth to Senescence: Results From a Multicenter Study Using a New Automated Chemiluminescence IGF-I Immunoassay Conforming to Recent International Recommendations. J. Clin. Endocrinol. Metab. 99, 1712-1721 (2014).

68. Savani, B. N. et al. Prolonged Chronic Graft-versus-Host Disease is a Risk Factor for Thyroid Failure in Long-Term Survivors After Matched Sibling Donor Stem Cell Transplantation for Hematologic Malignancies. Biol. Blood Marrow Transplant. 15, 377-381 (2009).

69. Lando, A. et al. Thyroid function in survivors of childhood acute lymphoblastic leukaemia: the significance of prophylactic cranial irradiation. Clin. Endocrinol. (Oxf.) 55, 21-25 (2001).

70. Holland, F. J., McCONNON, J. K., Volpe, R. \& Saunders, E. F. Concordant Graves' Disease after Bone Marrow Transplantation: Implications for Pathogenesis. J. Clin. Endocrinol. Metab. 72, 837-840 (1991).

71. Crowne, E. C. et al. Adrenocorticotrophin and cortisol secretion in children after low dose cranial irradiation. Clin. Endocrinol. (Oxf.) 39, 297-305 (1993).

72. Lam, K. S. et al. Symptomatic hypothalamic-pituitary dysfunction in nasopharyngeal carcinoma patients following radiation therapy: a retrospective study. Int. J. Radiat. Oncol. Biol. Phys. 13, 1343-1350 (1987).

73. Al-Anazi, K. A. et al. Acute Adrenal Insufficiency Induced by Total Body Irradiation in a Recipient of an Allogeneic Hematopoietic Stem Cell Transplantation. Cell Tissue Transplant. Ther. 2010, 5-10 (2010).

74. Savas-Erdeve, S. et al. Primary adrenal insufficiency in a child after busulfan and cyclophosphamide-based conditioning for hematopoietic stem cell transplantation. J. Pediatr. Endocrinol. Metab. JPEM 24, 853-855 (2011).

75. Ho, K. K. Y. \& on behalf of the 2007 GH Deficiency Consensus Workshop Participants. Consensus guidelines for the diagnosis and treatment of adults with GH deficiency II: a statement of the GH Research Society in association with the European Society for Pediatric Endocrinology, Lawson Wilkins Society, European Society of Endocrinology, Japan Endocrine Society, and Endocrine Society of Australia. Eur. J. Endocrinol. 157, 695-700 (2007).

76. Darzy, K. H., Thorner, M. O. \& Shalet, S. M. Cranially irradiated adult cancer survivors may have normal spontaneous $\mathrm{GH}$ secretion in the presence of discordant peak GH responses to stimulation tests (compensated GH deficiency). Clin. Endocrinol. (Oxf.) 70, 287-293 (2009).

77. Darzy, K. H. Radiation-induced hypopituitarism: Curr. Opin. Endocrinol. Diabetes Obes. 20, 342-353 (2013).

78. Agha, A. et al. Hypothalamic-Pituitary Dysfunction after Irradiation of Nonpituitary Brain Tumors in Adults. J. Clin. Endocrinol. Metab. 90, 6355-6360 (2005).

79. Samaan, N. A. et al. Hypothalamic, pituitary and thyroid dysfunction after radiotherapy to the head and neck. Int. J. Radiat. Oncol. Biol. Phys. 8, 1857-1867 (1982).

80. Brownstein, C. M. et al. Factors That Affect Final Height and Change in Height Standard Deviation Scores in Survivors of Childhood Cancer Treated with Growth Hormone: A Report from the Childhood Cancer Survivor Study. J. Clin. Endocrinol. Metab. 89, 4422-4427 (2004).

81. Ergun-Longmire, B. et al. Growth Hormone Treatment and Risk of Second Neoplasms in the Childhood Cancer Survivor. J. Clin. Endocrinol. Metab. 91, 3494-3498 (2006).

82. Vahl, N. et al. Continuation of growth hormone $(\mathrm{GH})$ replacement in $\mathrm{GH}$-deficient patients during transition from childhood to adulthood: a two-year placebo-controlled study. J. Clin. Endocrinol. Metab. 85, 1874-1881 (2000).

83. Wallace, W. H., Shalet, S. M., Crowne, E. C., Morris-Jones, P. H. \& Gattamaneni, H. R. Ovarian failure following abdominal irradiation in childhood: natural history and prognosis. Clin. Oncol. R. Coll. Radiol. G. B. 1, 75-79 (1989).

84. Phelan, R. et al. Ovarian function after hematopoietic cell transplantation: a descriptive study following the use of $\mathrm{GnRH}$ agonists for myeloablative conditioning and observation only for reduced-intensity conditioning. Bone Marrow Transplant. 51, 1369 (2016).

85. Schimmer, A. D. et al. Ovarian function after autologous bone marrow transplantation. J. Clin. Oncol. Off. J. Am. Soc. 
Clin. Oncol. 16, 2359-2363 (1998).

86. Decanter, C. et al. Anti-Müllerian hormone follow-up in young women treated by chemotherapy for lymphoma: preliminary results. Reprod. Biomed. Online 20, 280-285 (2010).

87. Brignardello, E. et al. Gonadal status in long-term male survivors of childhood cancer. J. Cancer Res. Clin. Oncol. 142, 1127-1132 (2016).

88. Anserini, P. et al. Semen analysis following allogeneic bone marrow transplantation. Additional data for evidencebased counselling. Bone Marrow Transplant. 30, 447-451 (2002).

89. Howell, S. J. \& Shalet, S. M. Spermatogenesis After Cancer Treatment: Damage and Recovery. JNCl Monogr. 2005, 1217 (2005).

90. Green, D. M. et al. Lack of Specificity of Plasma Concentrations of Inhibin B and Follicle-Stimulating Hormone for Identification of Azoospermic Survivors of Childhood Cancer: A Report From the St Jude Lifetime Cohort Study. J. Clin. Oncol. 31, 1324-1328 (2013).

91. Anandi, P. et al. Factors influencing the late phase of recovery after bone mineral density loss in allogeneic stem cell transplantation survivors. Bone Marrow Transplant. 51, 1101-1106 (2016).

92. Myers, K. C. et al. Poor growth, thyroid dysfunction and vitamin D deficiency remain prevalent despite reduced intensity chemotherapy for hematopoietic stem cell transplantation in children and young adults. Bone Marrow Transplant. 51, 980-984 (2016).

93. Glotzbecker, B. et al. Low levels of 25-hydroxyvitamin D before allogeneic hematopoietic SCT correlate with the development of chronic GVHD. Bone Marrow Transplant. 48, 593-597 (2013).

94. Matta, J. et al. Prévalence du surpoids, de l'obésité et des facteurs de risque cardio-métaboliques dans la cohorte CONSTANCES. Bull. Epidémiologique Hebd. 640-646 (2016).

95. INSERM, KANTAR HEALTH \& ROCHE. ObEpi 2012 - Enquête épidémiologique nationale sur le surpoids et l'obésité. (2012).

96. Halcox, J. P. et al. Prevalence and treatment of atherogenic dyslipidemia in the primary prevention of cardiovascular disease in Europe: EURIKA, a cross-sectional observational study. BMC Cardiovasc. Disord. 17, 160 (2017).

97. Bauduceau, B. et al. Epidemiology of the metabolic syndrome in 2045 French military personnel (EPIMIL study). Diabetes Metab. 31, 353-359 (2005).

98. Bastard, J. P. et al. What kind of simple fasting index should be used to estimate insulin sensitivity in humans? Diabetes Metab. 29, 285-288 (2003).

99. Alberti, K. G. \& Zimmet, P. Z. Definition, diagnosis and classification of diabetes mellitus and its complications. Part 1: diagnosis and classification of diabetes mellitus provisional report of a WHO consultation. Diabet. Med. J. Br. Diabet. Assoc. 15, 539-553 (1998).

100. Hirabayashi, K. et al. Risk factors for diabetes mellitus and impaired glucose tolerance following allogeneic hematopoietic stem cell transplantation in pediatric patients with hematological malignancies. Int. J. Hematol. 99, 477-486 (2014).

101. Oudin, C. et al. Metabolic syndrome in adults who received hematopoietic stem cell transplantation for acute childhood leukemia: an LEA study. Bone Marrow Transplant. 50, 1438-1444 (2015). 
DEMÉOCQ (Vianney) - Conséquences endocriniennes des greffes de cellules souches hématopoïétiques allogéniques - $50 \mathrm{f}$., tabl., schémas.

Th. : Méd. : Brest 2017

RESUME : Les progrès des greffes de moelle osseuse ont permis une augmentation significative du nombre de survivants d'hémopathies. Les complications post-greffes immédiates et tardives, notamment endocriniennes, nécessitent un dépistage précoce. Les conséquences endocriniennes sont peu évaluées chez l'adulte allogreffé. Notre étude rétrospective et monocentrique a évalué 45 patients allogreffés à l'âge adulte à 14,5 mois post-greffe en moyenne.

Elle avait pour objectif d'évaluer les conséquences hormonales, par des dosages statiques et dynamiques, osseuses et métaboliques, et de rechercher des critères prédictifs de survenue de ces anomalies.

L'atteinte gonadique est systématique chez les femmes et l'atteinte de la spermatogenèse touche la moitié des hommes. Presque la moitié des patients ont une atteinte antéhypophysaire (somatotrope, corticotrope, thyréotrope et/ou gonadotrope). 13,6 \% des patients présentent une dysthyroïdie (critère prédictif : âge $<30$ ans à l'allogreffe). La moitié est atteinte d'ostéopénie (critère prédictif : conditionnement par busulfan) et plus du quart d'ostéoporose. L'obésité (20\%) et la dyslipidémie (44\%) sont plus fréquentes que la population générale. II n'y a pas d'augmentation de l'insulino-résistance et la dyslipidémie est alors possiblement attribuable aux traitements anti-cancéreux ou aux immunosuppresseurs.

Un dépistage doit être proposé afin d'améliorer la qualité de vie des patients.

\section{MOTS CLES :}

ALLOGREFFE DE MOELLE OSSEUSE

INSUFFISANCE ANTE-HYPOPHYSAIRE

INFERTILITÉ

HYPOTHYROÏDIE

OSTEOPOROSE

DYSLIPIDÉMIE

INSULINORÉSISTANCE

\section{JURY :}

Président : M. BERTHOU

Membres : Me. KERLAN

M. DELARUE

Me. COUTURIER

Me. LESVEN

DATE DE SOUTENANCE :

4 octobre 2017

ADRESSE DE L'AUTEUR :

7 rue Saint Saëns - 29200 BREST 